\title{
Further Insights on the Influence of the Indian Ocean Dipole on the Following Year's ENSO from Observations and CMIP5 Models
}

\author{
NiCOLAS C. JOURDAIN \\ CNRS, LGGE, F-38402, and Université Grenoble Alpes, LGGE, F-38402 Grenoble, France, and ARC Centre of \\ Excellence for Climate System Science, University of New South Wales, Sydney, Australia \\ MATTHIEU LENGAigne \\ LOCEAN-IPSL, Sorbonne Université (UPMC, Université Paris 06)-CNRS-IRD-MNHN, Paris, France, and Indo-French Cell \\ for Water Sciences, IISc-NIO-IITM-IRD Joint International Laboratory, National Institute of Oceanography, Goa, India \\ JÉROME VIALARD AND TAKESHI IZUMO \\ LOCEAN-IPSL, Sorbonne Université (UPMC, Université Paris 06)-CNRS-IRD-MNHN, Paris, France
}

\section{ALEXANDER SEN GUPTA}

ARC Centre of Excellence for Climate System Science, and Climate Change Research Centre, University of New South Wales, Sydney, Australia

(Manuscript received 15 July 2015, in final form 30 October 2015)

\begin{abstract}
Recent observational studies have suggested that negative and positive Indian Ocean dipole (IOD) events (nIOD and pIOD, respectively) favor a transition toward, respectively, El Niño and La Niña events one year later. These statistical inferences are however limited by the length and uncertainties in the observational records. This paper compares observational datasets with twenty-one 155 -yr historical simulations from phase 5 of CMIP (CMIP5) to assess IOD and El Niño-Southern Oscillation (ENSO) properties along with their synchronous and delayed relationships. In the observations and most CMIP5 models, it is shown that El Niños tend to be followed by La Niñas but not the opposite, that pIODs co-occur more frequently with El Niños than nIODs with La Niñas, that nIODs tend to be followed by El Niños one year later less frequently than pIODs by La Niñas, and that including an IOD index in a linear prediction based on the Pacific warm water volume improves ENSO peak hindcasts at 14 months lead. The IOD-ENSO delayed relationship partly results from a combination of ENSO intrinsic properties (e.g., the tendency for El Niños to be followed by La Niñas) and from the synchronous IOD-ENSO relationship. The results, however, reveal that this is not sufficient to explain the high prevalence of pIOD-Niña transitions in the observations and $75 \%$ of the CMIP5 models, and of nIOD-Niño transitions in $60 \%$ of CMIP5 models. This suggests that the tendency of IOD to lead ENSO by one year should be explained by a physical mechanism that, however, remains elusive in the CMIP5 models. The ability of many CMIP5 models to reproduce the delayed influence of the IOD on ENSO is nonetheless a strong incentive to explore extended-range dynamical forecasts of ENSO.
\end{abstract}

\section{Introduction}

El Niño-Southern Oscillation (ENSO) is the dominant mode of climate variability at interannual time scales (e.g., McPhaden et al. 2006). El Niño events are

Corresponding author address: Nicolas C. Jourdain, Laboratoire de Glaciologie et Géophysique de l'Environnement, 54 rue Molière, Domaine Universitaire, BP96, 38402 St Martin d'Hères CEDEX, France. E-mail: njourdain@lgge.obs.ujf-grenoble.fr characterized by warm sea surface temperature anomalies (SSTAs) in the central and eastern tropical Pacific, associated with enhanced deep atmospheric convection and westerly wind anomalies in the western and central Pacific. ENSO emerges from internal dynamics of the ocean-atmosphere coupled system in the tropical Pacific, with climate impacts at an almost global scale through atmospheric teleconnections (e.g., Trenberth et al. 1998). These global climate impacts are a strong incentive for improved long-term forecasts of ENSO. 
ENSO, however, is associated with a complex set of ocean and atmosphere processes. Improving the skill of ENSO forecasts has thus remained a major challenge for the scientific community over the last 30 years.

The basic physics of the evolution of El Niño and La Niña events are now reasonably well understood [see the reviews by Wang and Picaut (2004), Collins et al. (2010), and Clarke (2014)]. The so-called Bjerknes feedback (Bjerknes 1969), a positive air-sea feedback loop in the Pacific, provides the necessary instability for an El Niño to develop, but favorable conditions are needed for the Bjerknes feedback to induce an El Niño event. In particular, the importance of heat stored in the upper tropical Pacific Ocean is now widely recognized within the framework of the recharge/discharge oscillator (Jin 1997; Wyrtki 1985; Meinen and McPhaden 2000). Prior to an El Niño, there is a buildup in the warm water volume (WWV, defined as the volume of seawater above the $20^{\circ} \mathrm{C}$ isotherm in the equatorial Pacific; Meinen and McPhaden 2000). This anomalously high WWV favors the growth of SSTAs during the ensuing El Niño, sustained by the Bjerknes feedback. The ENSO-WWV relationship appears to change on decadal or longer time scales (Lee and McPhaden 2010; Tang and Deng 2010; McPhaden 2012), as is the case with other ENSO characteristics such as its preferred frequency or spatial pattern (An and Wang 2000; Leloup et al. 2008; Wittenberg 2009). Izumo et al. (2014) nonetheless found that the WWV lead on ENSO was statistically significant over the period 1872-2008.

During an El Niño, the eastward shift of the Walker cell induces anomalous subsidence, increased downward surface shortwave fluxes, and reduced nearsurface wind over the Indian Ocean. This favors a tropical Indian Ocean basin (IOB)-wide warming during the peak of El Niño events (e.g., Klein et al. 1999; Ohba and Ueda 2005, 2009b) that is maintained throughout boreal summer by local air-sea interactions (e.g., Xie et al. 2009). The tropical Indian Ocean is also home to the Indian Ocean dipole (IOD; Reverdin et al. 1986; Saji et al. 1999; Murtugudde et al. 2000; Webster et al. 1999). A positive IOD (pIOD) is characterized by strong negative SSTA near the coast of Sumatra and weaker positive SSTA in the western Indian Ocean. Similar feedbacks to those occurring for ENSO in the Pacific explain the IOD growth during boreal summer until its peak in boreal fall (Saji et al. 1999; Cai and Cowan 2013), even though fundamental differences of air-sea interactions have been reported between the Pacific and Indian Ocean basins ( $\mathrm{Li}$ et al. 2003). There is now strong evidence

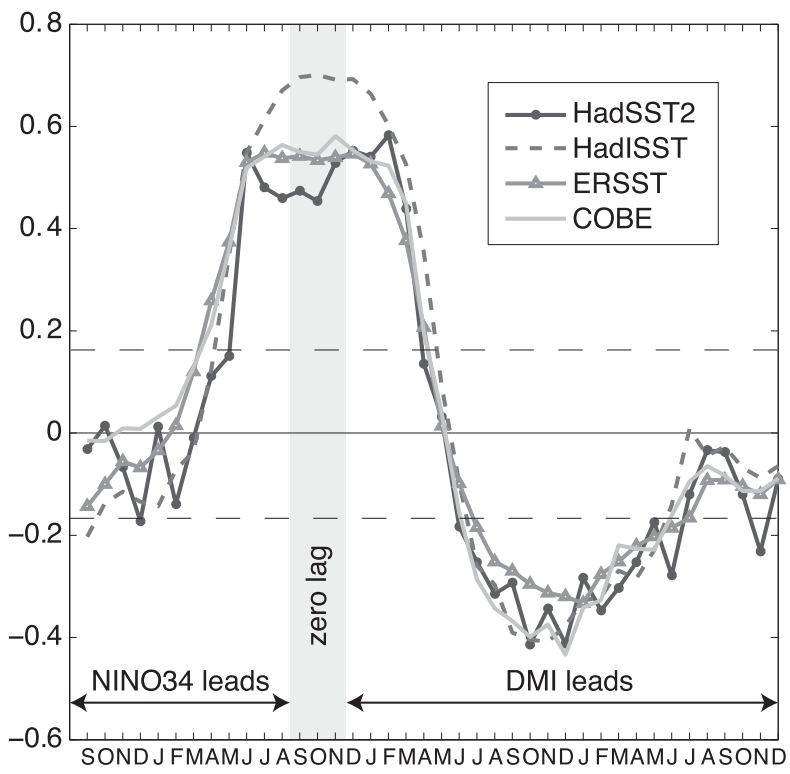

FIG. 1. Correlation between DMI in SON (show by the gray bar) and lagged monthly Niño-3.4 in four observational datasets over 1890-2012. The $90 \%$ significance level is indicated by the horizontal dashed lines [ $t$ test with 100 degrees of freedom, which corresponds to $123 \mathrm{yr}$ of data with a significant autocorrelation over 15 months as noted in Burgers (1999)].

that the IOD is an intrinsic mode of variability of the Indian Ocean (e.g., Annamalai et al. 2003; Fischer et al. 2005; Behera et al. 2006; Luo et al. 2008, 2010). El Niño events do, however, have a tendency to trigger pIOD events because of the easterly wind anomalies that they favor over the eastern equatorial Indian Ocean (Annamalai et al. 2003). As a result, pIODs often co-occur with El Niño events and negative IODs (nIODs) co-occur with La Niña events (Annamalai et al. 2003; Li et al. 2003; Ashok et al. 2003; Bracco et al. 2005; Fischer et al. 2005; Behera et al. 2006). This relationship between codeveloping IOD and ENSO events (hereafter referred to as the synchronous IOD-ENSO relationship) is highlighted by the $\sim 0.5-0.7$ correlation between the ENSO and IOD indices in boreal fall (correlation at zero lag in Fig. 1). A decadal modulation of the IOD has been noted by Tozuka et al. (2007) and Ummenhofer et al. (2009). The strength of the synchronous IOD-ENSO relationship also undergoes interdecadal variability, as shown by Yuan and Li (2008), Santoso et al. (2012), and Izumo et al. (2014), who all noted a weaker IOD-ENSO relationship over the period 1950-70 than over the recent period.

Distinct asymmetries exist between the positive and negative phases of both ENSO and IOD, in terms of their intensity, duration, and/or phase transition (e.g., 
Ohba and Ueda 2009a; Okumura et al. 2011; Ohba and Watanabe 2012; Choi et al. 2013). The intensity of both ENSO and IOD is asymmetric in that the amplitude of El Niño (pIOD) events tends to be larger than the amplitude of La Niña (nIOD) events (Burgers and Stephenson 1999; Jin et al. 2003; Wu et al. 2010; Cai et al. 2012). There is also an asymmetry in the duration of ENSO events: most El Niño events terminate rapidly after their peak, whereas La Niña events tend to persist into the following year (Ohba and Ueda 2009a; Ohba et al. 2010; Okumura et al. 2011). Finally, ENSO exhibits a transition asymmetry, whereby there is a higher probability for El Niño to be followed by La Niña the following year than vice versa (Ohba et al. 2010; Choi et al. 2013).

Previous studies have proposed that variability in the Indian Ocean sector could influence ENSO during the following year (e.g., Meehl 1987; Clarke and van Gorder 2003; Kug and Kang 2006). For instance, it has been suggested that the IOB could foster a rapid transition from El Niño to La Niña (Kug and Kang 2006; Ohba and Ueda 2007, 2009a; Kug and Ham 2012; Santoso et al. 2012; Ohba and Watanabe 2012) by favoring the development of easterly wind anomalies over the western Pacific in winter (Annamalai et al. 2005; Dayan et al. 2015). Similarly, Izumo et al. (2010) have suggested that IOD events could be precursors of ENSO. Based on satellite data, they showed that positive (negative) IODs tended to be followed by La Niña (El Niño) events approximately 14 months later (Fig. 1). They demonstrated significant skill in predicting ENSO events 14 months in advance by jointly using IOD and WWV as predictors in a simple linear regression model. Hereafter, this influence of the IOD on following year's ENSO state is referred to as the delayed IOD-ENSO relationship. Izumo et al. (2010) suggested the following mechanism to explain that delayed relationship. The warm anomaly in the eastern Indian Ocean associated with a negative IOD induces an easterly anomaly in the equatorial Pacific. This negative anomaly and the associated wind signal over the Pacific abruptly disappear in November-December at the termination of the IOD event. The equatorial wave response to this wind anomaly and its sudden relaxation drives an eastward current anomaly in the western-central equatorial $\mathrm{Pa}$ cific. The latter favors the onset of a delayed El Niño by pushing the warm pool eastward. This IOD influence interacts with the intrinsic Pacific WWV preconditioning. For example, an nIOD can interact constructively with positive WWV conditions to favor the onset of an El Niño. More recently, Izumo et al. (2015) suggested that the IOD may reinforce the IOB tendency to favor ENSO phase transition. When IOD and IOB events co-occur, the abrupt IOD eastern pole demise at the end of fall indeed favors a faster development of IOB-induced wind anomalies in the western Pacific in winter-spring. As predicted by linear wave theory, this faster wind change enhances the central Pacific SST response by $\sim 25 \%-50 \%$ relative to the sole IOB influence.

The analysis of Izumo et al. (2010) was based on only $\sim 30$ years of data. A later study (Izumo et al. 2014) explored the robustness of the delayed IOD-ENSO relationship over the 1872-2008 period using IOD and ENSO indices based on an optimal combination of sparse historical observations, and an efficient proxy of WWV interannual variations based on the temporal integral of Pacific zonal wind stress. They found that a linear hindcast model based on both the dipole mode index (DMI; see section 2) and WWV proxies in SeptemberNovember (SON) can explain $\sim 50 \%$ of the variance of the ENSO peak 14 months in advance, with significant contributions from both IOD and WWV over the historical period.

Uncertainties however remain about the mechanism proposed by Izumo et al. (2010) as the relationship between the IOD and ENSO-independent wind anomalies in the western Pacific is not robust across all wind products (Dayan et al. 2014). In addition, the significance tests used by Izumo et al. (2010) did not account for the biennial tendency of the IOD and the tendency of the IOD to co-occur with ENSO. Taken together these tendencies could partly explain why IODs precede ENSOs without the need for a physical mechanism; that is, ENSO often induces a positive IOD and transition to La Niña the following year, hence resulting in a lead relation between a positive IOD and La Niña that is not necessarily associated with a causality. In addition, very little work has been done on the transition asymmetry of the delayed IOD-ENSO relationship despite the existence of asymmetries between the positive and negative phases of both ENSO and IOD.

While oceanic and atmospheric observational data have a good accuracy and spatial sampling since the beginning of the satellite era, they do not resolve the main patterns of the IOD or ENSO very well before the 1980s (e.g., Izumo et al. 2014). On the other hand, phase 5 of the Coupled Model Intercomparison Project (CMIP5) offers a large database in which IOD-ENSO relationships can be tested based on long temporal series. Many CMIP5 models produce reasonable ENSO amplitude and spatial SST patterns (Kim and Yu 2012; Bellenger et al. 2014; Taschetto et al. 2014). The CMIP5 models also capture the IOD variability, despite a tendency to overestimate its amplitude (Cai and Cowan 2013). Models from the previous phase of CMIP (CMIP3) 
had similar skills to CMIP5 models in terms of ENSO and IOD characteristics (Bellenger et al. 2014; Cai and Cowan 2013); most of them did not capture the transition/duration asymmetry of ENSO (Ohba et al. 2010). Despite the IOD and ENSO biases in individual models, the CMIP5 ensemble provides an opportunity to sample the diversity of ENSO and IOD behaviors.

In this paper, we use twenty-three 155-yr CMIP5 simulations to assess the robustness of the IOD-ENSO relationships and the asymmetry of their temporal sequences, as well as to question the physical or statistical nature of their origin. After a brief presentation of the datasets and methods (section 2), we show that many characteristics of ENSO, IOD, and their synchronous relationship are correctly represented in a majority of the 23 CMIP5 models analyzed in this study (section 3). In section 4, we show that the CMIP5 delayed IODENSO relationship is also in good agreement with observations, and that the use of an IOD index significantly enhances hindcast skill scores of the ENSO peak 14 months later. We also demonstrate that the delayed IOD-ENSO relationship does not seem to be just a statistical artifact and therefore needs to be explained, at least partly, by a physical mechanism. Finally, we highlight the importance of ENSO asymmetries for the delayed IOD-ENSO relationship.

\section{Datasets and methods}

We use four monthly SST gridded products based on ship and buoy observations:

- Hadley Centre Sea Surface Temperature, version 2 (HadSST2), covers the period from 1850 onward at $5^{\circ}$ resolution and there is no interpolation to fill grid cells where there are no observations (Rayner et al. 2006).

- HadISST covers the period from 1870 onward at $1^{\circ}$ resolution and optimal interpolation is used to produce a complete spatial coverage (Rayner et al. 2003).

- The Centennial In Situ Observation-Based Estimates (COBE) SST covers the period from 1850 onward at $1^{\circ}$ resolution and optimal interpolation is used for gridding purposes (Ishii et al. 2005).

- The Extended Reconstructed Sea Surface Temperature, version $3 b$ (ERSST.v3b), covers the period from 1854 onward at a $2^{\circ}$ resolution with a gridding technique based on empirical orthogonal function projections [see Smith et al. (2008) about ERSST.v3, but note that ERSST.v3b does not include satellite data].

There are large uncertainties in these four datasets before the 1880s due to lack of observations (Yasunaka and Hanawa 2011), so only the period $1890-2012$ is considered in this paper.
To estimate WWV over the observed period (see definition in the introduction), we first use the 19802012 monthly WWV time series provided by the TAO Project Office, NOAA/PMEL (Meinen and McPhaden 2000). In addition, we calculate monthly WWV from the Simple Ocean Data Assimilation reanalysis (SODA2.2.4) that covers the period 1871-2008 (Carton and Giese 2008). The correlation between the SeptemberNovember time series of SODA WWV and NOAABMRC WWV is 0.97 over the overlapping period (1980-2008), demonstrating that the SODA reanalysis is adequate for estimating WWV variability, at least over the recent period. The correlation between SODA SON WWV and the SON WWV proxy derived in Izumo et al. (2014) is 0.39 over 1890-2001 and 0.67 over 1980-2001, which is far from perfect knowing that both are constrained by the same wind stress product [Twentieth Century Reanalysis (20CR); Compo et al. 2011]. The SODA SON WWV compares much better with an "independent" WWV (correlation of 0.69 over 1890-2000, and 0.90 over 1980-2000) calculated from a regional ocean reanalysis covering the tropical Pacific and based on a different ocean model, wind forcing, and assimilation scheme than SODA (Tang and Deng 2010). All the aforementioned correlations have a $p$ value lower than 0.01 , as estimated using effective numbers of degrees of freedom based on autocorrelation calculations.

Finally, we analyze 23 historical CMIP5 simulations in which greenhouse gas, aerosol, and ozone concentrations are prescribed to follow observations spanning $\sim 1850$ 2005 (Taylor et al. 2011). The various models used in this paper are listed in Table 1. More CMIP5 models are available, but the three-dimensional data needed to calculate WWV (which is needed for our study) were not available for these models at the time of writing. Some of the models we consider only differ by their grid resolution or the parameterization of certain physical processes: for instance, IPSL-CM5A-LR and IPSL-CM5A-MR are based on the same code but are run at two different resolutions. Some models have a common oceanic component (e.g., ACCESS1.0 and GFDL CM3) or a common atmospheric component (e.g., GFDL-ESM2M and GFDLESM2G; CCSM4 and NorESM1-M; and ACCESS1.0 and HadGEM2-ES), even though the exact version of these common components often differs. In this paper, we only consider the first ensemble member of each model.

ENSO is characterized through the Niño-3.4 index (SST anomalies averaged over $5^{\circ} \mathrm{S}-5^{\circ} \mathrm{N}, 170^{\circ}-120^{\circ} \mathrm{W}$ ) and the IOD is examined through the DMI defined by Saji et al. (1999). The IOB is characterized through the tropical Indian Ocean index (TIO; defined as SST anomalies averaged over $30^{\circ} \mathrm{S}-25^{\circ} \mathrm{N}, 20^{\circ}-120^{\circ} \mathrm{E}$ ). Considering both CMIP3 and CMIP5 models, Cai and 
TABLE 1. CMIP5 model names, providing institutes, and related reference. (Expansions of acronyms are available online at http://www. ametsoc.org/PubsAcronymList.)

\begin{tabular}{|c|c|c|}
\hline Model & Institute & References \\
\hline ACCESS1.0 & CSIRO-BoM, Australia & BOM (2010) \\
\hline CanESM2 & CCCma, Canada & Chylek et al. (2011) \\
\hline CCSM4 & NCAR, United States & Gent et al. (2011) \\
\hline CNRM-CM5 & CNRM-CERFACS, France & Voldoire et al. (2013) \\
\hline FGOALS-g2 & LASG-Center for Earth System Science China & Yongqiang et al. (2004) \\
\hline FGOALS-s2 & LASG/IAP, China & Yongqiang et al. (2004) \\
\hline GFDL CM3 & NOAA/GFDL, United States & Donner et al. (2011) \\
\hline GFDL-ESM2G & NOAA/GFDL, United States & Donner et al. (2011) \\
\hline GFDL-ESM2M & NOAA/GFDL, United States & Donner et al. (2011) \\
\hline GISS-E2-H & NASA GISS, United States & Schmidt et al. (2006) \\
\hline HadCM3 & Met Office, United Kingdom & Collins et al. (2001) \\
\hline HadGEM2-CC & Met Office, United Kingdom & Martin et al. (2011) \\
\hline HadGEM2-ES & Met Office, United Kingdom & Collins et al. (2011) \\
\hline INM-CM4.0 & Institute of Numerical Mathematics, Russia & Volodin et al. (2010) \\
\hline IPSL-CM5A-LR & IPSL, France & Dufresne et al. (2013) \\
\hline IPSL-CM5B-LR & IPSL, France & Dufresne et al. (2013) \\
\hline IPSL-CM5A-MR & IPSL, France & Dufresne et al. (2013) \\
\hline MIROC5 & $\begin{array}{l}\text { Atmosphere and Ocean Research Institute } \\
\text { (AORI)-National Institute for Environmental } \\
\text { Studies (NIES)-JAMSTEC, Japan }\end{array}$ & Watanabe et al. (2010) \\
\hline MIROC-ESM-CHEM & AORI-NIES-JAMSTEC, Japan & Watanabe et al. (2011) \\
\hline MPI-ESM-LR & MPI for Meteorology, Germany & Raddatz et al. (2007) \\
\hline MPI-ESM-MR & MPI for Meteorology, Germany & Raddatz et al. (2007) \\
\hline MRI-CGCM3 & Meteorological Research Institute, Japan & Yukimoto et al. (2001) \\
\hline NorESM1-M & Norwegian Climate Centre, Norway & Bentsen et al. (2012) \\
\hline
\end{tabular}

Cowan (2013) have found a cross-model correlation of 0.89 between DMI amplitude and the IOD amplitude calculated using the principal component of Indian Ocean SST anomalies. This suggests that the use of these simple DMI and Niño-3.4 indices is able to capture with reasonable fidelity the covariation of ENSO and IOD despite structural biases in the models. To isolate interannual variability and exclude interdecadal and lower frequency variability, all indices are filtered by removing the Hann-filtered time series using averaging weights of 1.0 in the center of the 11yr running window, 0.75 at \pm 2 years, and 0.25 at \pm 4 years. Most of the results presented in this paper were compared against a simple 7-yr window running average (i.e., over $\pm 3 \mathrm{yr})$ and results were very similar to using the Hann filter.

Classical techniques like composites or Pearson correlations can be misleading because the indices are asymmetric (e.g., ENSO exhibits a positive skewness). The meaning of the standard deviation thus varies across the models, as well as the proportion of positive and negative phases, which makes model intercomparisons complex. Here, we use a different approach: positive phases (pIOD and El Niño) are defined as part of the upper quartile of the index distribution, while negative phases (nIOD and La Niña) are defined as part of the lower quartile. These thresholds correspond approximately to $60 \%-80 \%$ of the standard deviation. This framework allows a fair comparison of phase transitions between models and observations because there are $25 \%$ of positive and negative phases for every dataset. The positive and negative phases are defined for the peak months, that is, November-January (NDJ) for Niño-3.4 and SON for DMI. We use a Monte Carlo method to estimate if a given phase transition (e.g., from El Niño to La Niña) is significantly different from a random process. To that end, we generate $10^{5}$ synthetic time series by randomly resampling the actual time series (with replacement). If, say, less than $10 \%$ of the synthetic time series present more transitions from an El Niño to a La Niña than the actual time series, we consider that the El Niño-La Niña transition is significantly different from a random transition at the $90 \%$ significance level. For example, $25 \%$ of El Niño events would be followed by a La Niña if the transition were purely random and the time series were infinitely long. But because the CMIP5 time series are only 155 years long, the Monte Carlo method indicates that the transition can be considered as nonrandom at the $90 \%$ significance level if more than $\sim 34 \%$ or less than $\sim 16 \%$ of El Niño events are followed by a La Niña.

\section{IOD and ENSO in the CMIP models}

To assess the mechanism proposed by Izumo et al. (2010) in the CMIP5 models, it is important to ascertain that these models accurately reproduce IOD and ENSO 

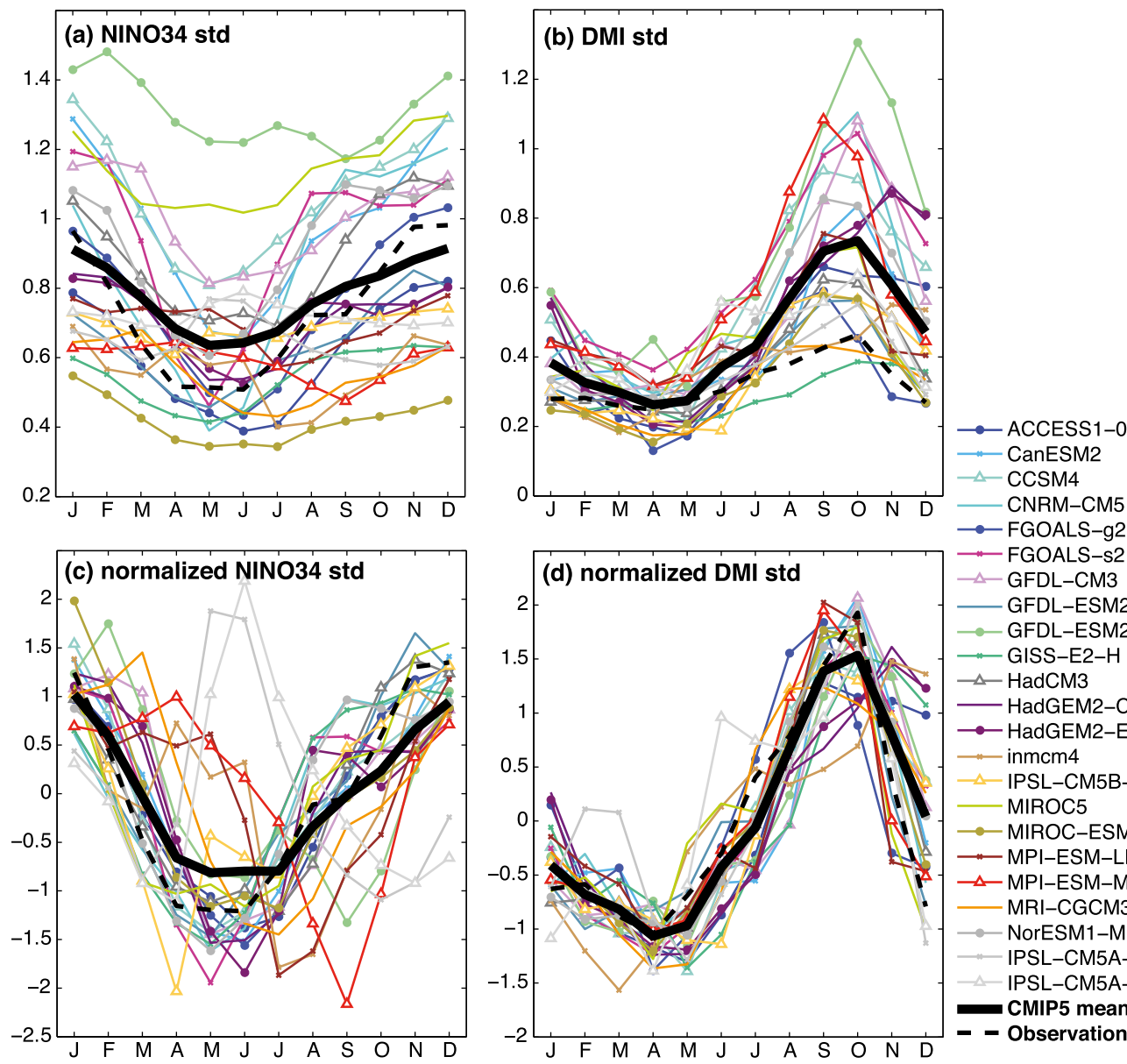

$\longrightarrow$ FGOALS-g2

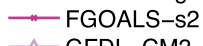

$\triangle-$ GFDL-CM3

GFDL-ESM2G
- GFDL-ESM2M

—-GISS-E2-H

$\triangle-\mathrm{HadCM} 3$

- HadGEM2-CC

$\rightarrow$ HadGEM2-ES

— inmcm4

$\longrightarrow$ IPSL-CM5B-LR

MIROC5

$\longrightarrow$ MIROC-ESM-CHEM

$\longrightarrow$ MPI-ESM-LR

$\triangle-$ MPI-ESM-MR

- MRI-CGCM3

$\because$ NorESM1-M

—IPSL-CM5A-LR

$\rightarrow$ IPSL-CM5A-MR

CMIP5 mean

FIG. 2. Standard deviation of (a) Niño-3.4 and (b) DMI for 23 CMIP5 models (color lines), the CMIP5 multimodel mean (solid black), and the observational multidataset mean (dashed black), in kelvin. (c),(d) As in (a),(b), but the curve is normalized (anomaly with respect to the mean, divided by the standard deviation).

seasonal phase locking and spatial patterns (section 3a). The recharge mechanism (i.e., lead-lag relation between WWV and ENSO) and biennial tendency of ENSO are then assessed in section 3b. Finally, the synchronous relation of the IOD and ENSO, as well as its phase asymmetry, is evaluated in section 3c.

\section{a. Seasonal phase locking and spatial patterns}

The monthly standard deviation of Niño-3.4 and DMI are displayed in Fig. 2 for the 23 CMIP5 models and observations. As noted in previous studies (Taschetto et al. 2014; Bellenger et al. 2014), the intermodel spread in Niño-3.4 peak amplitude (in NDJ) is very large, the latter being underestimated by $20 \%-50 \%$ in 13 models and overestimated by $10 \%-50 \%$ in 9 models (Fig. 2a). To emphasize ENSO seasonality rather than its amplitude, Fig. 2c shows the normalized amplitude of the Niño-3.4 seasonal cycle. In most models the Niño-3.4 variance correctly peaks in austral summer or early spring, except for the IPSL-CM5A-LR and IPSL-CM5A-MR (Fig. 2c). The duration of the peak however lasts too long in a number of models, extending into February-March (INM-CM4.0, MRI-CGCM3, and the two MPI models) or into September-October (NorESM1-M, GISS-E2-H, and CNRM-CM5), as already noted by Jourdain et al. (2013) and Taschetto et al. (2014). Consequently, the 23model-mean underestimates Niño-3.4 amplitude in NDJ and overestimates it in April-June (AMJ).

Consistent with Cai and Cowan (2013), we find that 21 out of 23 CMIP5 models overestimate the DMI peak amplitude (in SON, Fig. 2b), the two exceptions being GISS-E2-H and MRI-CGCM3. The majority of models nonetheless peak in SON. In the following, we retain only 21 CMIP5 models, excluding IPSL-CM5A-LR and IPSL-CM5A-MR from our analysis because, as noted above, they have a highly unrealistic ENSO seasonality (Fig. 2c), and secondary DMI peaks in austral spring and winter (Fig. 2d). 

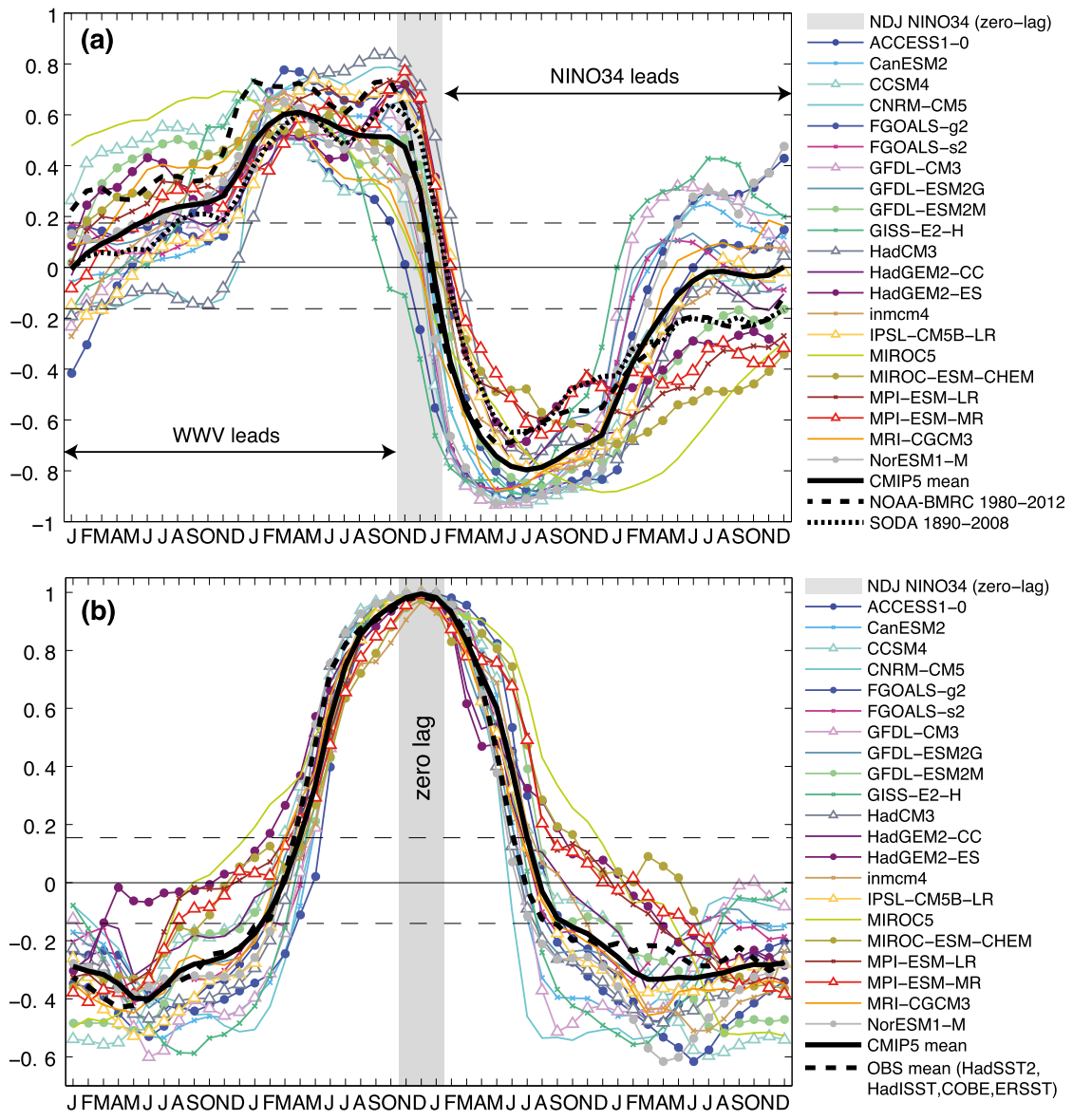

FIG. 3. (a) Correlation between Niño-3.4 in NDJ (gray bar) and lagged monthly WWV for 21 CMIP5 models (colors), the CMIP5 multimodel mean (solid black), the SODA reanalysis (long-dashed black), and the NOAA-BMRC observational dataset (short-dashed black). (b) Autocorrelation between Niño-3.4 in NDJ (gray bar) and lagged monthly Niño-3.4 for 21 CMIP5 models (colors), the CMIP5 multimodel mean (solid black), and the multiobservation mean (dashed black). The $90 \%$ level of statistical significance for 100 degrees of freedom is indicated by the dashed line (see caption of Fig. 1).

As found in Taschetto et al. (2014) and Jourdain et al. (2013), the 21 CMIP5 models generally realistically simulate largest Niño-3.4 SST anomalies in the eastern and central Pacific, but the SST anomaly extends too far west and has a too narrow meridional extent (not shown). Consistently with SST anomalies, ENSO wind anomalies are underestimated in the central Pacific and overestimated in the far western part of the basin in most models (not shown). The IOB pattern appears in SST regressions on Niño-3.4 (not shown). As found by Cai and Cowan (2013), the two poles of the IOD display a realistic location in the 21 CMIP5 models, but the IOD signal is stronger than observed (not shown).

\section{b. ENSO sequences}

We first assess the relationship between equatorial Pacific warm water buildup and ENSO across CMIP5 models. The selected CMIP5 models all simulate a warm water recharge/discharge associated with ENSO: the correlation between MAM WWV and the following NDJ Niño-3.4 ranges between 0.45 and 0.75 for the 21 models versus 0.70 for NOAA-BMRC over 1980-2010 and 0.60 for SODA over 1890-2008. All CMIP5 models and observational datasets also exhibit a statistically significant negative correlation between the peak of ENSO and the WWV 2-3 seasons after (Fig. 3a), indicative of a WWV discharge (or recharge for La Niña events) starting at the ENSO peak. For a few models, this WWV discharge however occurs too early, in particular for GISS-E2-H and ACCESS1.0. A few other models (e.g., MIROC5) also simulate an unrealistic warm water buildup more than a year before the ENSO peak (Fig. 3a). Overall, however, the multimodel mean agrees well with the observations. 


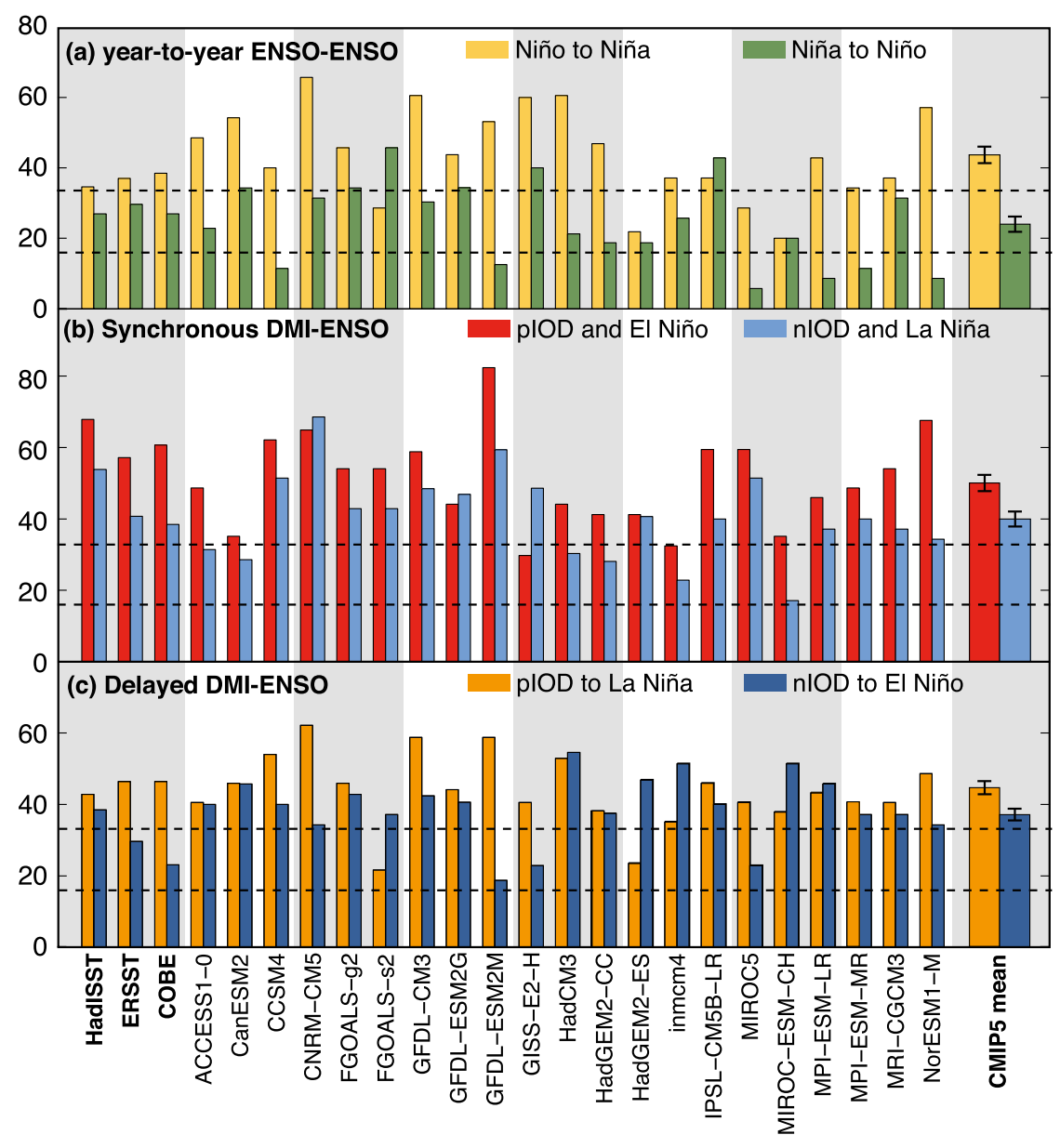

FIG. 4. (a) Proportion (\%) of El Niños followed by La Niña (yellow) and of La Niñas followed by El Niño (green). (b) Proportion of pIODs immediately followed by El Niño (red) and of nIODs immediately followed by La Niña (blue). (c) Proportion of pIODs followed by La Niña 14 months later (orange) and of nIODs followed by El Niño 14 months later (blue). The bars falling between the two dashed lines cannot be considered as different from the random proportion of $25 \%$ ( $90 \%$ confidence interval based on Monte Carlo statistical method; see text). The rightmost column represents the CMIP5 multimodel mean, and the error bars indicate the $90 \%$ confidence interval on the mean ( $t$ value, all CMIP5 distributions being normally distributed at the $99 \%$ confidence level according to a Shapiro-Wilk test).

We now further investigate the biennial tendency of ENSO. The CMIP5 multimodel ENSO autocorrelation exhibits a remarkable agreement with observations, with a tendency of ENSO to flip its phase every year (Fig. 3b). Despite this overall agreement, a few individual models fail to reproduce this biennial behavior (MIROC models, MPI-ESM models, and HadGEM2ES). In addition, some CMIP5 models display an autocorrelation after the peak that remains significant a few months longer than in the observations, an indication that ENSO events tend to have a late termination in these models, as previously noted by Leloup et al. (2008) for the CMIP3 models. This linear technique based on autocorrelation does not allow an assessment of the transition asymmetries between El Niño and La Niña. To that end, we calculate the percentage of El Niño events followed by a La Niña, and vice versa. Observations and CMIP5 multimodel ensemble (with confidence exceeding the $p=0.10$ level) show that the percentage of El Niños followed by La Niñas is significantly larger than what would be expected from a random transition (Fig. 4a). On the other hand, the proportion of La Niñas followed by El Niños is not significantly distinguishable from a random sequence in observations and the CMIP5 multimodel mean (Fig. 4a). This asymmetry in ENSO transition is also captured by most CMIP5 models: 19 out of 21 models (FGOALS-s2 and IPSL-CM5B-LR excepted) show more transitions from El Niño to La 


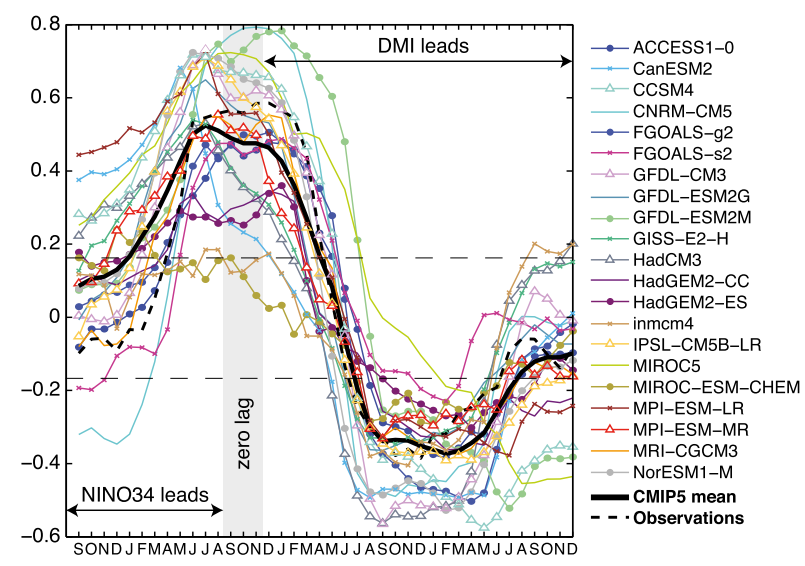

FIG. 5. Correlation between DMI in SON (shown by the gray bar) and lagged monthly Niño-3.4 in 21 CMIP5 models. The $90 \%$ significance level is indicated by the horizontal dashed lines ( $t$ test for 100 degrees of freedom; see caption of Fig. 1).

Niña than from La Niña to El Niño (Fig. 4). The CMIP5 multimodel mean (with confidence exceeding the $p=$ 0.10 level) and a majority of the models nonetheless tend to overestimate the occurrence of El Niño-La Niña transitions. The relatively good representation of the asymmetry in ENSO phase transitions in CMIP5 may indicate some improvement from CMIP3 for which Ohba et al. (2010) reported significant biases.

\section{c. Synchronous IOD-ENSO relationship}

In this subsection, we investigate the ability of CMIP5 models to simulate the tendency for pIOD (nIOD) to co-occur with El Niño (La Niña). As shown in Fig. 5, 19 out of 21 models produce a significant synchronous correlation between DMI and Niño-3.4 (exceptions are MIROC5 and INM-CM4.0). For a majority of models, this correlation ranges within \pm 0.15 of the observed one. For the observations, this positive correlation starts being significant around May during the early development of the IOD event. By contrast, the positive correlation starts being significant earlier in most CMIP5 models, and half of them simulate an unrealistically high correlation between SON DMI and the previous year's NDJ Niño-3.4. For a few models (e.g., MIROC and MPI models), this feature is likely related to the overestimated persistence of ENSO events until the following SON (Fig. 3b). The intermodel variations in the strength of the synchronous IOD-ENSO relationship is significantly related to the intermodel variations in ENSO amplitude (correlation of 0.56; not shown), as well as to the intermodel variations in IOD amplitude (correlation of 0.46). There is also a significant crossmodel correlation between the amplitude of ENSO and the amplitude of IOD (correlation of 0.62 ; not shown) likely due to the similar mechanisms involved in both modes of variability (Liu et al. 2014; McPhaden and Nagura 2014) or to the fact that IOD can be triggered by ENSO.

We now assess asymmetries in the synchronous IODENSO relationship. If the DMI and Niño-3.4 were randomly distributed, $25 \%$ of pIODs (defined as upper quartile DMI events) would occur synchronously with an El Niño event, and $25 \%$ with a La Niña event. Instead, $57 \%-68 \%$ of observed pIODs are associated with an El Niño event in the observations (Fig. 4). Two-thirds of the models and the multimodel mean (with confidence exceeding the $p=0.10$ level) underestimate the occurrence of pIOD-El Niño transitions. The latter is nonetheless significantly larger than what would be expected from a random transition (as is the nIOD-La Niña transition). The observed proportion of nIODs associated with a La Niña event is $38 \%-54 \%$ (i.e., weaker than the opposite transition, but still significantly higher than what a purely random processes would produce). The multimodel ensemble reproduces this asymmetry along with a large majority of the 21 models (Fig. 4b): only three models exhibit an opposite asymmetry (most pronounced in the GISS-E2-H).

\section{IOD as an early precursor of ENSO}

We now assess the ability of CMIP5 models to simulate the tendency for IOD events to be followed by an ENSO event in the following year (Izumo et al. 2010, 2014). We then discuss whether the delayed IODENSO relationship can be explained by a statistical artifact arising from the intrinsic properties of ENSO sequences and the synchronous IOD-ENSO relationship. Finally, we investigate the possibility of a physical mechanism.

\section{a. Statistical relationship and transition asymmetry}

All CMIP5 models except MIROC5 simulate a significant negative correlation between DMI in SON and Niño-3.4 14 months later, as in the observations (Fig. 5) and as previously described by Izumo et al. (2010). Correlation coefficients are slightly weaker than observed in two-thirds of CMIP5 models, but reach -0.50 in six models (versus -0.40 in the observations). Contrary to the synchronous correlation, the intermodel variations in CMIP5 delayed correlations are related to neither ENSO $(r=-0.15)$ nor IOD $(r=0.04)$ amplitude, and there is no relationship between the synchronous and delayed correlations across the models $(r=$ $0.00)$. There is a transition asymmetry in this delayed IOD-ENSO relationship: the delayed pIOD-La Niña transitions are more frequent than the delayed nIOD-El 

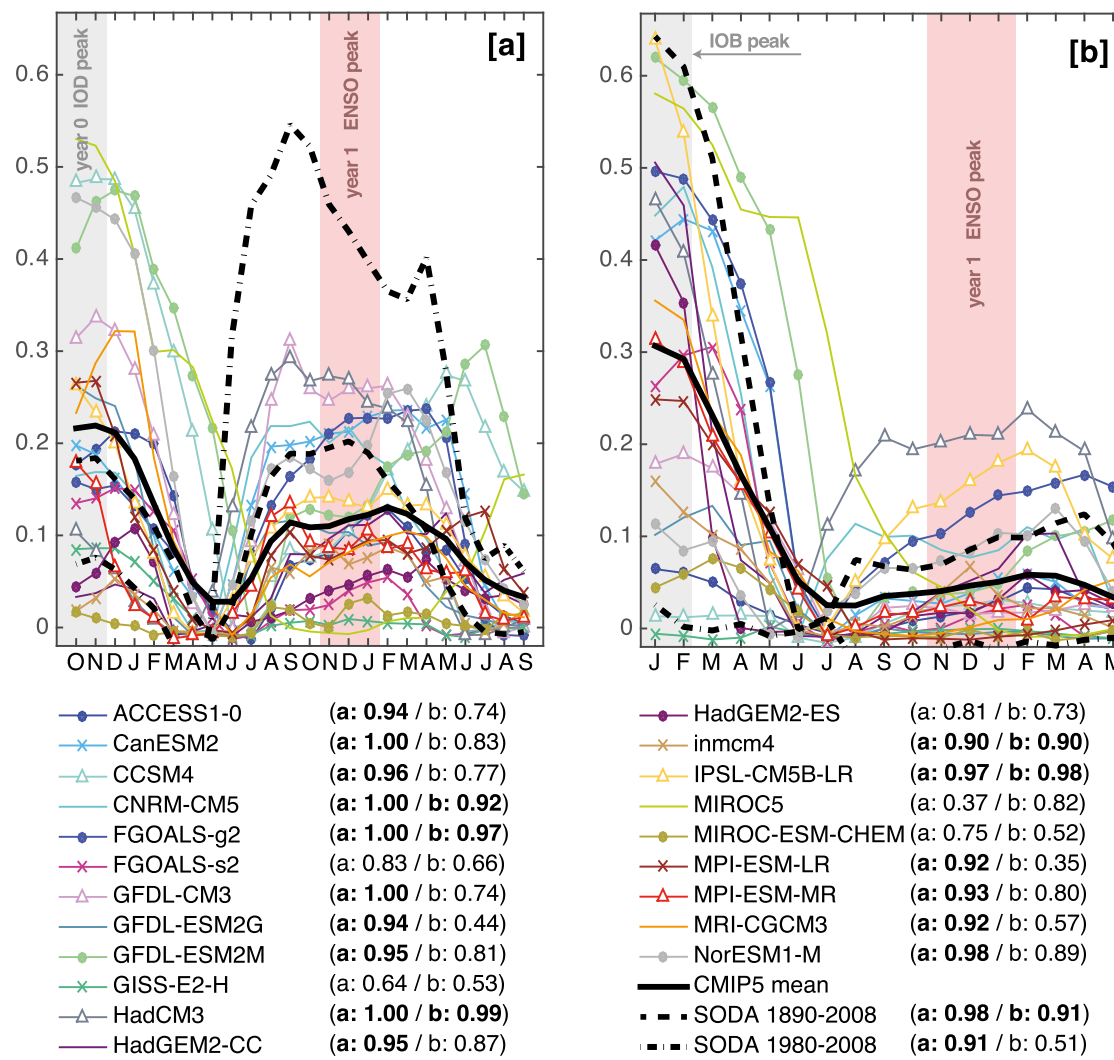

FIG. 6. Increase of explained Niño-3.4 variance when a second predictor of ENSO is used in addition to WWV. (a) Increased variance due to DMI (i.e., first predictor is SON WWV and second predictor is SON DMI). (b) Increased variance due to TIO [i.e., first predictor is January-February (JF) WWV and second predictor is JF TIO]. The plot shows the mean value over $10^{5}$ cross-validations leaving $50 \%$ of the samples (randomly chosen) to train the prediction model and keeping $50 \%$ for its evaluation. The significance of the increase in variance obtained from this method is indicated within brackets (bold when $90 \%$ significant). The date on which the forecast is issued is indicated by the gray bar, and the peak of ENSO in NDJ of year 1 is indicated by the light red bar.

Niño transitions in the observations $(43 \%-46 \%$ vs $23 \%-$ $38 \%$; Fig. 4c). The multimodel mean and two-thirds of the individual models are able to capture this asymmetry $(44 \% \pm 1 \%$ vs $38 \% \pm 1 \%$ for the multimodel mean; Fig. 4c). The delayed pIOD-La Niña transitions are significantly more frequent (at the $90 \%$ level) than what would be expected from a random process in all the observational products, in the multimodel mean and in 19 out of 21 individual models. The delayed nIOD-El Niño transition is above this limit for one observational product only (HadISST), for 18 models, and for the multimodel mean.

To assess the potential influence of IOD events on ENSO one year later, we compare 14-month lead linear statistical ENSO hindcasts based on WWV only with hindcasts based on WWV and DMI. Our approach is similar to Izumo et al. (2010) except that we use a more challenging cross-validation method, leaving $50 \%$ of the dataset to "train" the prediction scheme and keeping $50 \%$ for its evaluation [versus "leave one out" in Izumo et al. (2010)]. The training/evaluation partition is randomly resampled $10^{5}$ times to achieve statistical robustness. For each resampled set, we calculate the hindcast correlation skill score for one (WWV) or two (WWV and DMI) predictors at various lags, and the results are expressed in terms of enhanced explained Niño-3.4 variance (Fig. 6a). The explained Niño-3.4 variance in SODA is increased by $\sim 40 \%$ when DMI is included as a predictor over the period 1980-2008. This is a strong increase, even though this is slightly lower than the $\sim 60 \%$ found by Izumo et al. (2010, their Fig. 1), mostly because we use a more challenging cross-validation method (not shown). The increase in explained variance is much weaker over the period $1890-2008$, reaching only $\sim 20 \%$, which could be due to interdecadal variability or to the fact that SODA is 
poorly constrained by observations over the late nineteenth and early twentieth centuries. The CMIP5 multimodel mean correlation skills are similar to the SODA correlation skills over 1890-2008 when both WWV and DMI are used (not shown). The inclusion of DMI as predictor of ENSO increases the explained Niño-3.4 variance by $12 \%$ in the multimodel mean, and by up to $25 \%$ in HadCM3 and GFDL CM3 (Fig. 6a). The inclusion of DMI as a predictor of the following year's ENSO significantly increases the Niño-3.4 explained variance at the $90 \%$ level in 16 out of 21 CMIP5 models (see legend of Fig. 6). The enhanced predictability resulting from the inclusion of TIO (IOB index) is comparatively lower (Fig. 6b), which is likely due to the strong correlation between IOB and ENSO. This will be addressed in the discussion section.

We now analyze whether there is an asymmetry in the enhanced ENSO predictability resulting from the inclusion of DMI as a predictor. We consider that a hindcast is successful when the predicted phase corresponds to the actual phase. In the SODA reanalysis over the period 1890-2008 and in the CMIP5 ensemble, $50 \%$ of the linear hindcasts from WWV and DMI are successful for both El Niño and La Niña (Fig. 7a). This percentage is much larger than the $25 \%$ chance of success that would arise from a random process. To further assess the uncertainty on these proportions for the observations, we have accounted for an observational uncertainty of $\pm 0.2 \mathrm{~K}$ on both DMI and Niño-3.4 (http://stateoftheocean.osmc.noaa.gov/sur/ind/ dmi.php and http://stateoftheocean.osmc.noaa.gov/sur/ pac/nino34.php) by recalculating $10^{5}$ times the percentage of successful predictions but adding random perturbations in the range $\pm 0.2 \mathrm{~K}$ to both DMI and Niño-3.4. This calculation gives the $90 \%$ confidence intervals for the two proportions: $42 \%-58 \%$ of successful El Niño predictions and $42 \%-54 \%$ of successful La Niña predictions. Hence, an asymmetry leading to a difference of $16 \%$ or less between the proportion of successful El Niño and the proportion of successful La Niña predictions would be undetectable over the observed period because of observational uncertainties and short observational records. The CMIP5 ensemble exhibits a very small asymmetry in success rate, with $51.7 \%$ successful La Niña hindcasts versus $48.6 \%$ successful El Niño hindcasts (Fig. $7 b$ ). Only four individual models have a higher success rate for El Niño hindcasts than for La Niña hindcasts (HadGEM2-ES, INM-CM4.0, MPI-ESM-LR, and MRICGCM3; not shown). Among the 17 other models with a higher success rate for La Niña hindcasts, the difference in success rate between El Niño and La Niña hindcasts is smaller than $4 \%$ in 5 models, and smaller
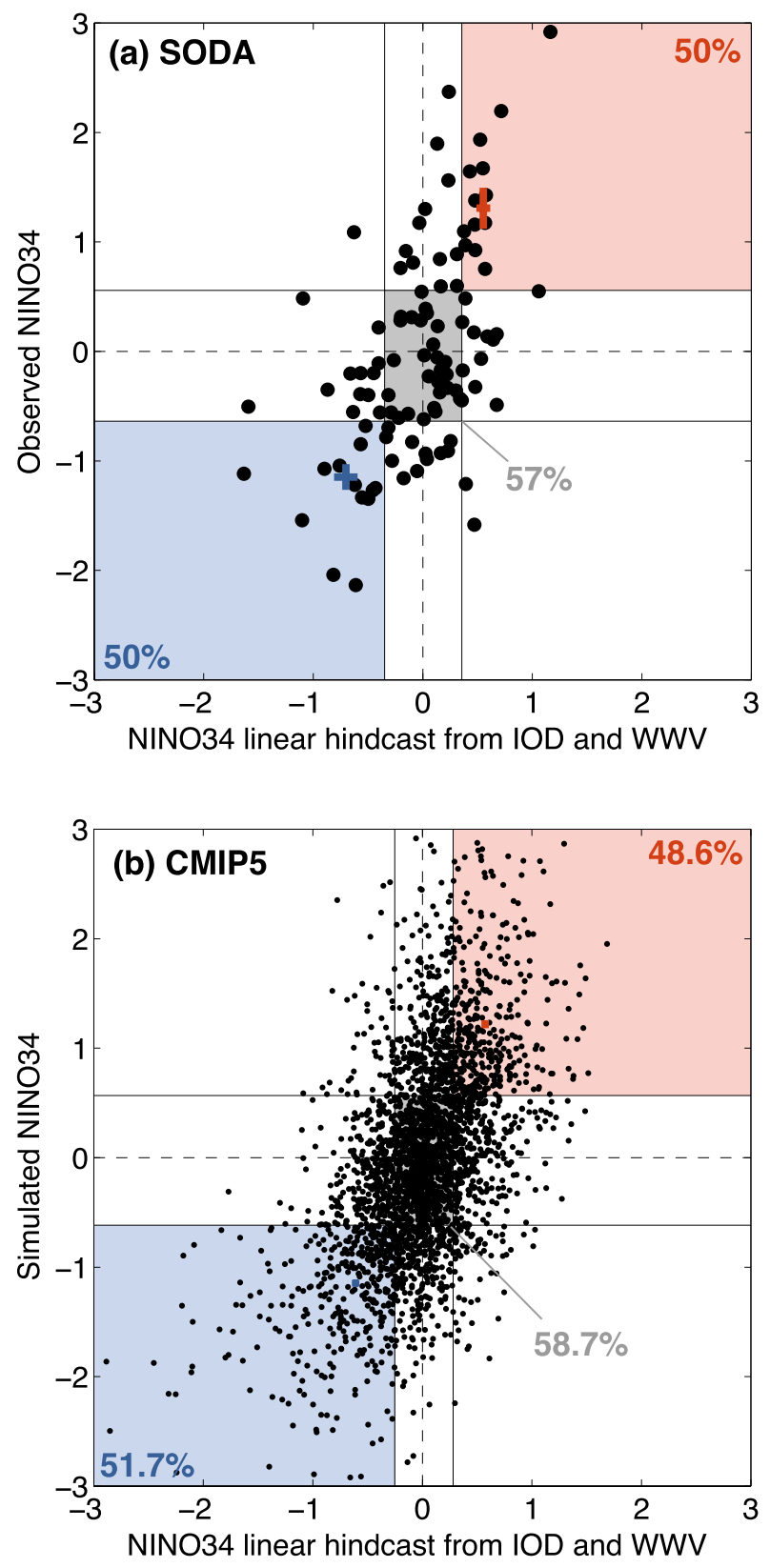

FIG. 7. (a) Niño-3.4 values in SODA ( $y$ axis) vs Niño-3.4 hindcasts based on a linear function of WWV and DMI 14 months before $(x$ axis). (b) As in (a), but for the 21 CMIP5 simulations together. The solid lines indicate the upper and lower quartiles defining El Niño and La Niña events. The shaded areas indicate successful hindcasts of La Niña (blue), neutral (gray), and El Niño events. The ratio of successful hindcasts is indicated for each shaded area. The mean values of the points located in each shaded area are indicated by a cross, and the size of each segment of the cross corresponds to the $90 \%$ confidence interval on the mean ( $t$ test).

than $10 \%$ in 9 of the 12 other models. Overall, prediction of La Niña phases appears slightly more successful than the prediction of El Niño phases in the CMIP5 models, but the difference is so small that 
accounting for this asymmetry is probably useless in an operational context.

\section{b. First approach to test the IOD influence on the following year's ENSO: Probabilities}

We now question whether the delayed IOD-ENSO relationship derived from our analysis could purely be a statistical artifact (i.e., unrelated to a physical process linking the IOD and ENSO one year later). For instance, an El Niño tends to synchronously induce a pIOD in the Indian Ocean, but also tends to be followed by a La Niña: this results in a tendency for pIOD events to precede a La Niña event without the need of an actual influence of the IOD on following year's ENSO. Our null hypothesis is hence that delayed relationships between IOD and ENSO can entirely arise from the intrinsic properties of ENSO temporal sequences and the synchronous ENSO-IOD relationship, without the need to invoke a physical mechanism for the delayed IOD-ENSO relationship. If the null hypothesis were true, the proportion $\mathscr{P}$ of pIODs followed by a La Niña 14 months later and the proportion of nIODs followed by an El Niño 14 months later would be given by

$$
\begin{aligned}
\mathscr{P}\left(\mathrm{pIOD}_{y 0} \rightarrow \operatorname{nina}_{y 1}\right)= & \mathscr{P}\left(\operatorname{pIOD}_{y 0} \rightarrow \operatorname{nina}_{y 0}\right) \cdot \mathscr{P}\left(\operatorname{nina}_{y 0} \rightarrow \operatorname{nina}_{y 1}\right) \\
& +\mathscr{P}\left(\operatorname{pIOD}_{y 0} \rightarrow \operatorname{neut}_{y 0}\right) \cdot \mathscr{P}\left(\text { neut }_{y 0} \rightarrow \text { nina }_{y 1}\right) \\
& +\mathscr{P}\left(\operatorname{pIOD}_{y 0} \rightarrow \operatorname{nino}_{y 0}\right) \cdot \mathscr{P}\left(\text { nino }_{y 0} \rightarrow \text { nina }_{y 1}\right)
\end{aligned}
$$

and

$$
\begin{aligned}
\mathscr{P}\left(\mathrm{nIOD}_{y 0} \rightarrow \operatorname{nino}_{y 1}\right)= & \mathscr{P}\left(\mathrm{nIOD}_{y 0} \rightarrow \operatorname{nina}_{y 0}\right) \cdot \mathscr{P}\left(\text { nina }_{y 0} \rightarrow \operatorname{nino}_{y 1}\right) \\
& +\mathscr{P}\left(\text { nIOD }_{y 0} \rightarrow \text { neut }_{y 0}\right) \cdot \mathscr{P}\left(\text { neut }_{y 0} \rightarrow \text { nino }_{y 1}\right) \\
& +\mathscr{P}\left(\text { nIOD }_{y 0} \rightarrow \text { nino }_{y 0}\right) \cdot \mathscr{P}\left(\text { nino }_{y 0} \rightarrow \text { nino }_{y 1}\right),
\end{aligned}
$$

where $y 0$ and $y 1$ denote year 0 and year 1 and, for example, $\mathscr{P}\left(\mathrm{pIOD}_{y 0} \rightarrow\right.$ nina $\left._{y 1}\right)$ is the probability for a pIOD to be followed by a delayed La Niña (i.e., peaking 14 months later $)$, whereas $\mathscr{P}\left(\mathrm{pIOD}_{y 0} \rightarrow\right.$ nina $\left._{y 0}\right)$ is the probability for a pIOD to be followed by a synchronous La Niña (i.e., peaking 2-3 months later).

Let us first examine the case of pIOD transitions to a $\mathrm{La}$ Niña in the following year [Eq. (1)]. Our null hypothesis is tested in Fig. 8a showing the scatterplot of the actual probability for a delayed pIOD-La Niña transition versus the probability calculated from the right-hand side in Eq. (1). The actual probability is greater than the one derived from Eq. (1) for all the observational products and 20 out of 21 CMIP5 models. This is a clear indication that the tendency for pIODs to co-occur with an El Niño and for El Niño events to be followed by a La Niña cannot alone explain the tendency for pIOD to precede La Niña 14 months later. This means that we can reject the null hypothesis for the delayed pIOD-La Niña transition in both the observations and the CMIP5 models. Let us now examine the opposite transition, that is, from a nIOD to an El Niño in the following year [Eq. (2)]. The actual probability is greater than the one derived from Eq. (2) for 18 out of 21 CMIP5 models, but there is no agreement across the observational products (Fig. 8a). This means that we can reject the null hypothesis for the delayed nIOD-El Niño transition in most CMIP5 models but not in the observations.
Another interesting feature in Fig. 8a is that the actual probabilities of delayed pIOD-La Niña transitions are highly correlated with the ones expected from Eqs. (1) and (2) across the CMIP5 models $(r=0.85)$. This indicates that even if the null hypothesis is rejected, a significant part of the delayed pIOD-La Niña relationship actually results from intrinsic properties of ENSO sequences and the synchronous IOD-ENSO relationship. Further investigations of the contribution of the various terms in Eq. (1) indicate that this high correlation is tightly related to the high probability of El Niños preceding La Niñas combined with the high probability of pIOD co-occurring with El Niño [third line of Eq. (1); not shown]. The delayed nIOD-El Niño relationship exhibits a different behavior in the sense that the actual probability is not highly correlated with the RHS in Eq. (2) (Fig. 8a). This is mostly because nIOD tends to cooccur with La Niña, but only a small proportion of $\mathrm{La}$ Niña events are followed by El Niño, so most delayed nIOD-El Niño transitions occur when nIOD co-occurs with a neutral ENSO event (not shown).

\section{c. Second approach to test the IOD influence on the following year's ENSO: Synthetic time series}

To test the robustness of the conclusions derived from the previous analysis an alternative method is examined using synthetic time series instead of phase probabilities. 


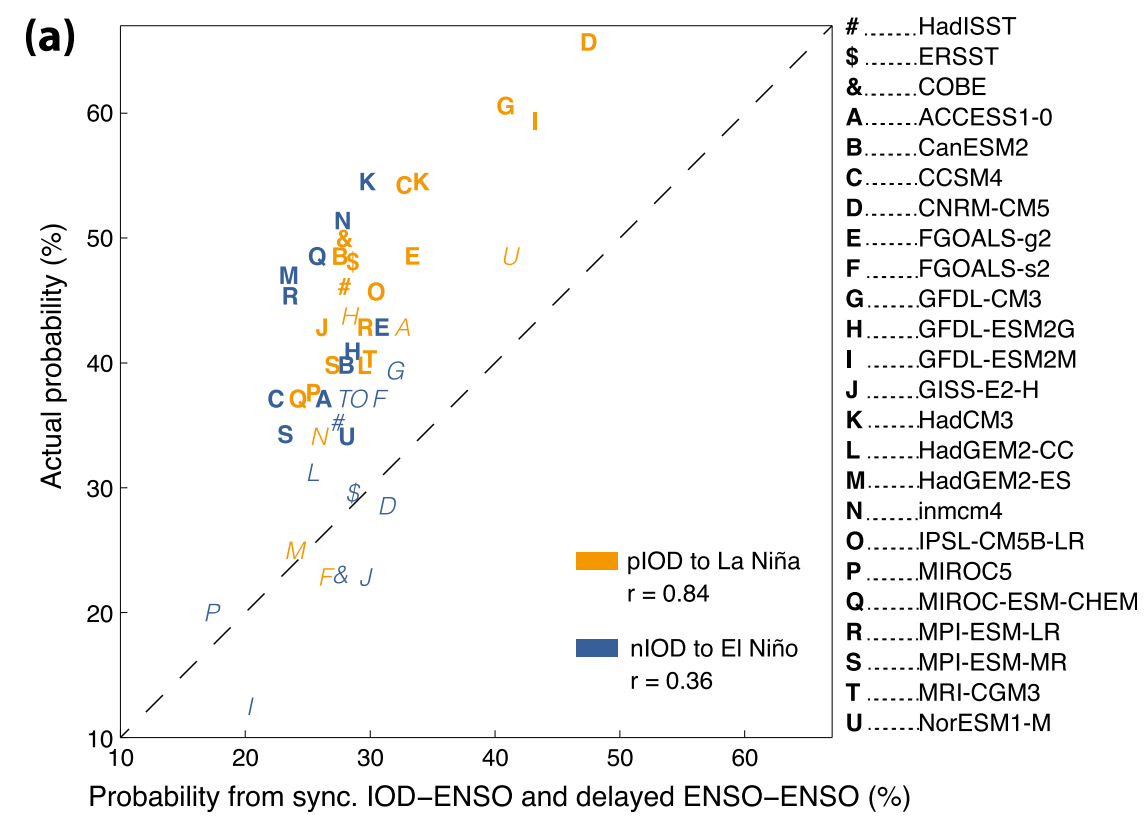

(b)

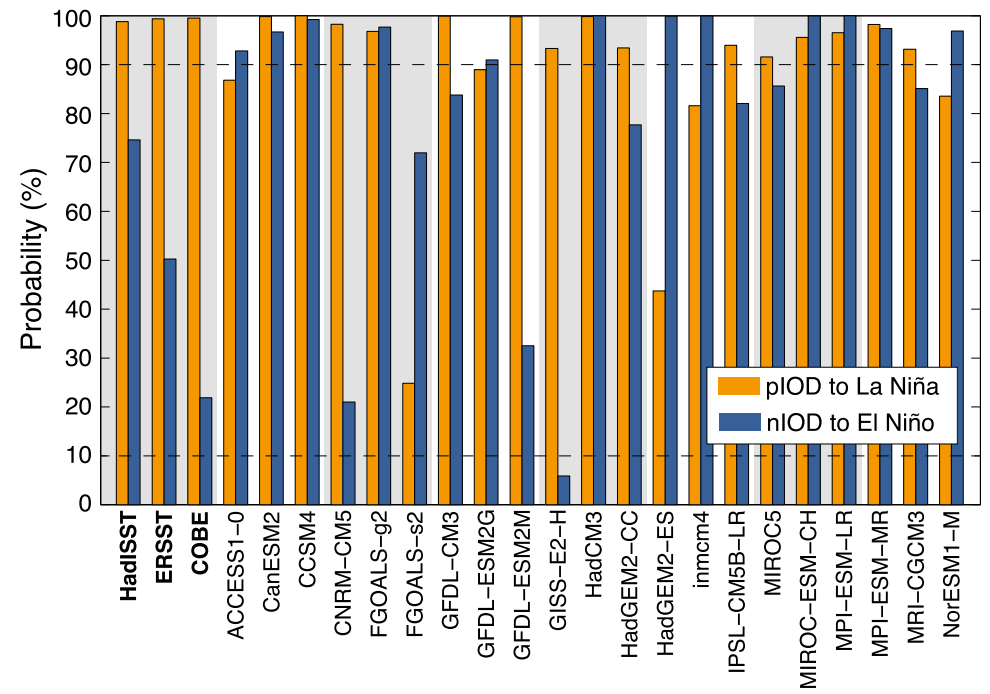

FIG. 8. (a) Scatterplot of the actual probability of the delayed pIOD-La Niña and nIOD-La Niña transitions ( $y$ axis) vs the probability calculated from Eqs. (1) and (2) ( $x$ axis). The crossmodel correlation coefficient $r$ is indicated for both transitions. The characters are displayed as bold when the null hypothesis is also rejected at the $90 \%$ confidence level when using the second method [see (b)], and in italic otherwise. (b) Probability to have a synthetic DMI time series [see Eq. (4)] with a proportion of delayed pIOD-La Niña (orange) and nIOD-El Niño (blue) transitions lower than the actual proportion in the observed and modeled time series. This probability can be considered as the statistical confidence level for rejecting the null hypothesis related to our second method (see text). The $10 \%$ and $90 \%$ levels are indicated with dashed lines.

Our null hypothesis is again that the delayed relationships between the IOD and ENSO can arise from the intrinsic properties of ENSO sequences and a synchronous linear ENSO-IOD relationship, without the need for a physical mechanism in the delayed IOD-ENSO relationship. Here we also assume the synchronous IOD-ENSO relationship is linear. To test our null hypothesis, we extract the residuals $\varepsilon(y)$ from the following 
linear fit to Niño-3.4 time series from individual CMIP5 models or observations:

$$
\operatorname{DMI}(y)=\hat{k} \operatorname{NINO} 34(y)+\varepsilon(y),
$$

where $\operatorname{DMI}(y)$ is the SON DMI time series, NINO34(y) the NDJ Niño-3.4 time series (of the same year), and $\hat{k}$ a constant parameter obtained from a least-mean-square calculation for each observed or CMIP5 dataset. Then we assume that residuals $\varepsilon$ result from random processes, and we randomly resample $\varepsilon$ to build $10^{4}$ synthetic DMI time series:

$$
\mathrm{DMI}_{\text {synth }}(y)=\hat{k} \mathrm{NINO} 34(y)+\varepsilon(r)
$$

where $r$ is a random index.

To investigate whether Eq. (3) can account for the statistics of the delayed IOD-ENSO relationship in the individual CMIP5 models and observations, we first calculate the proportions of delayed pIOD-La Niña and nIOD-El Niño in every synthetic time series. Then, we calculate the probability (across the $10^{4}$ time series) of obtaining a smaller proportion of delayed IOD-ENSO transitions than the actual one. This calculation gives the statistical significance for a rejection of the null hypothesis. For example, if $90 \%$ of the synthetic proportions are smaller than the actual one, we consider that the null hypothesis for this transition can be rejected at the $90 \%$ confidence level. This second method provides a better quantification of the results than the first method, but relies on an assumption of linearity (i.e., no asymmetry in synchronous IOD-ENSO transitions). Note that very similar results to the ones presented below are obtained if the model of Eq. (3) also accounts for intrinsic biennial tendency of the DMI [i.e., a term $\hat{k}_{2} \operatorname{DMI}(y-1)$ is added in the right-hand side of Eqs. (3) and (4); not shown]. We also obtained very similar results when accounting for first-order nonlinearity by fitting DMI on $\hat{k}_{1} \operatorname{NINO} 34(y)+\hat{k}_{2} \operatorname{NINO} 34(y)^{2}$ instead of $\hat{k} \operatorname{NINO} 34(y)$ (not shown).

For the observational products, we find that the null hypothesis is rejected at the $99 \%$ confidence level for the delayed pIOD-La Niña transition, which means that the observed transition occurs more often than in $99 \%$ of the synthetic time series (Fig. 8b). By contrast, the null hypothesis cannot be rejected for the observed delayed nIOD-El Niño transition: the statistical confidence level for the rejection is less than $75 \%$; that is, the observed transition occurs less often than in more than $25 \%$ of the synthetic time (Fig. 8 b). These observationbased results are consistent with those obtained in the previous subsection and suggest that there might be a physical mechanism amplifying the effects of the internal sequential properties of ENSO and the synchronous IOD-ENSO relationship on the delayed pIOD-La Niña transitions.

We also find that the null hypothesis is rejected at the $90 \%$ confidence level in 15 CMIP5 models for the delayed pIOD-La Niña transition, and in 12 models for the delayed nIOD-El Niño transition (Fig. 8b). These results suggest that in more than half of the CMIP5 models there might be a physical mechanism increasing the proportions of pIOD-La Niña and of nIOD-El Niño delayed transitions, but that its influence may be stronger or more common for the former transition. The results for CMIP5 are also consistent with the results from the previous subsection: both the orange and blue "clouds" in Fig. 8a are above the 1:1 line, and the models for which the null hypothesis cannot be rejected even at low confidence levels in the second approach are the same models that are close to the 1:1 line (see italicized characters in Fig. 8a). Overall, this second method also suggests that the intrinsic properties of ENSO sequences and the synchronous IOD-ENSO relationship alone are not sufficient to explain the high prevalence of delayed IOD-ENSO transitions. Hence this strongly suggests that a physical mechanism may influence the transition from IOD to ENSO in the following year.

\section{d. Physical mechanism}

We now investigate whether the physical mechanism proposed by Izumo et al. (2010) to explain the influence of the IOD on the following year's ENSO is evident in the CMIP5 models. As this mechanism was originally based on the analysis of a relatively short time period (1981-2009), we first reproduce their analysis (their Fig. 2) using SODA and 20CR over the entire 1890-2008 period and over 1980-2008 (Figs. 9c,d). In this analysis, the delayed response to the IOD is obtained by lagged multiple linear regression of a selection of variables onto DMI and Niño-3.4 of year 0, and the signals induced by synchronous ENSO is removed by only considering the regression coefficient related to DMI (see figure caption). By this procedure, we also removed most of the signature of the IOB that co-occurs with the peak of ENSO at year 0 and 1 because it is highly correlated with Niño-3.4 (see discussion section). The SST anomalies associated with the developing phase of a negative IOD event (June-October year 0) increase easterly winds in the western and central equatorial Pacific. Composites of 500-hPa vertical velocity indicate that this wind anomaly is consistent with an amplification of the Walker circulation that would be caused by the eastern pole of the IOD (not shown). In the mechanism proposed by Izumo et al. (2010), the easterly wind anomalies force a downwelling Rossby 

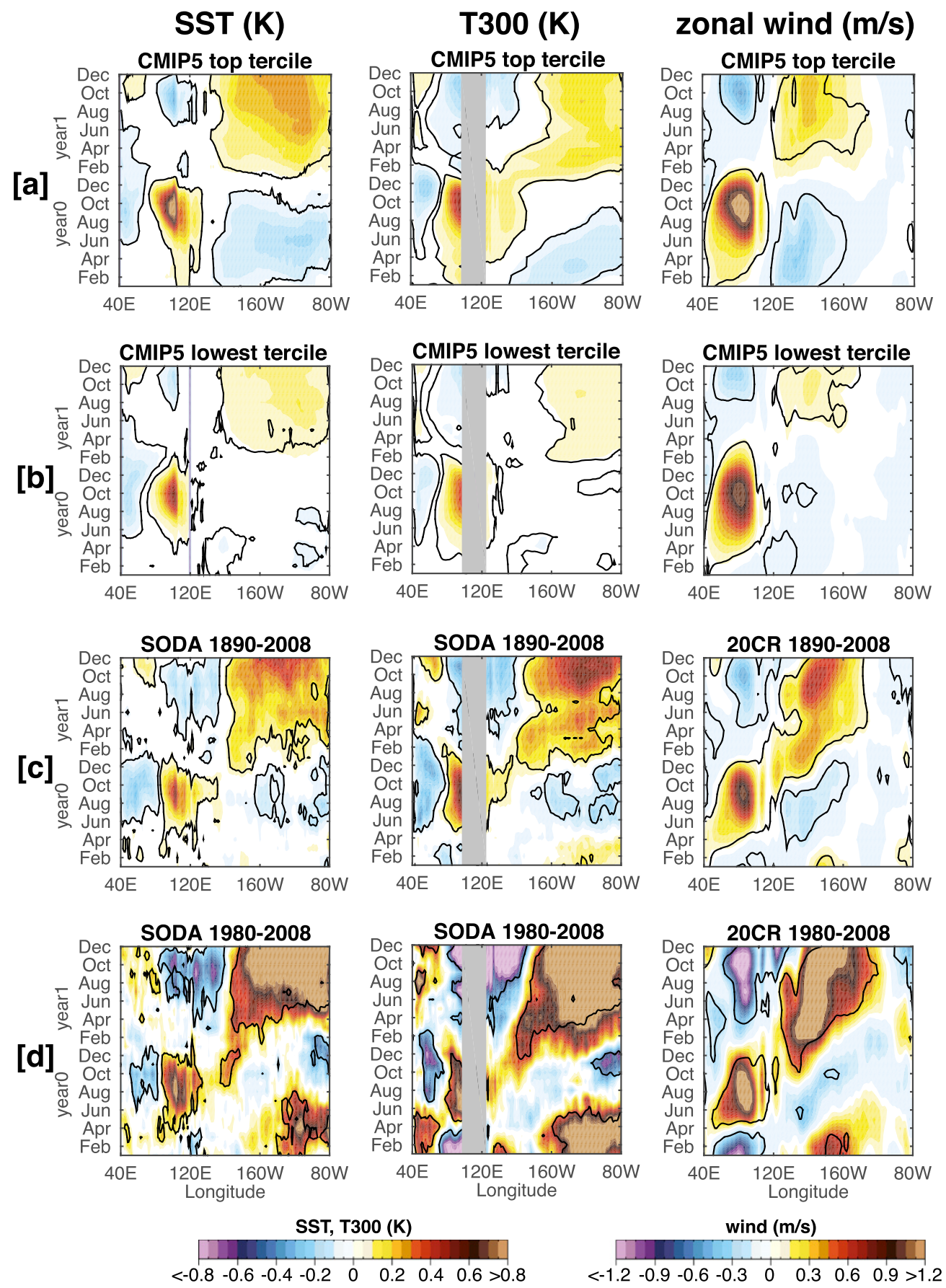

FIG. 9. Longitude-time sections showing the influence of SON DMI on equatorial Indo-Pacific SSTs (averaged over $10^{\circ} \mathrm{S}-0^{\circ}$ in the Indian Ocean and $5^{\circ} \mathrm{S}-5^{\circ} \mathrm{N}$ in the Pacific), equatorial temperature over $0-300 \mathrm{~m}$ (T300, averaged between $3^{\circ} \mathrm{S}$ and $3^{\circ} \mathrm{N}$ ), and zonal wind (averaged between $3^{\circ} \mathrm{S}$ and $3^{\circ} \mathrm{N}$ ). The linear influence of synchronous NDJ Niño-3.4 is removed as follows. For any variable $Y$ (SST, T300, or zonal wind), we calculate the coefficients of the following multilinear regression: $Y=a \widehat{\mathrm{DMI}}+b \overline{\mathrm{NINO} 34}$, with the tilde $(\sim)$ denoting nondimensional variables (divided by their standard deviation), and $-a$ is plotted here to illustrate the case of a negative IOD (even though positive IODs are also accounted for in this plot). Gray shading indicate no data for T300. (a) The CMIP5 multimodel mean anomaly based on the best tercile of models in terms of enhanced predictability of ENSO from DMI (according to Fig. 6c) is shown. (b) As in (a), but for the lowest CMIP5 tercile. Multimodel mean composites consist of the average of regression coefficients from individual models. The two lower rows are based on SODA and 20CR over (c) 1890-2008 and (d) 1980-2008. The black contours indicate the 90\% confidence level (multimodel mean for CMIP5). 
wave that contributes to the buildup of heat in the western Pacific (see T300 in Figs. 9c,d), providing an efficient preconditioning for an El Niño onset (recharged state). They also force an upwelling Kelvin wave that reflects at the eastern boundary as an upwelling Rossby wave, favoring eastward currents in the central Pacific a couple of months later (delayed advectivereflective feedback; Picaut et al. 1997) and hence positive SST anomalies that can favor the onset of an El Niño. As shown by Izumo et al. (2015), changes in western Pacific zonal wind stress from boreal summer-fall to winterspring matter as much as the actual stress anomaly in winter-spring for the development of spring SST anomalies in the central Pacific. The occurrence of an IOD always enhances the change from summer-fall to winter-spring in western Pacific zonal wind stress, as explained below for the case of a nIOD (either "pure" or associated with a basinwide cooling). In the case of a pure nIOD event (i.e., no IOB as in Fig. 9), the eastern IOD pole disappearance in late November of year 0 induces a relaxation of the easterly anomaly in the western Pacific. This favors positive SST anomaly at the beginning of year 1 in the central Pacific (Figs. 9c,d). In the case of a nIOD co-occurring with the development of an IOB cooling, the western pole (a signature associated with the IOB) and eastern poles of the IOD tend to have compensating effects on winds in the western Pacific (Annamalai et al. 2005). In such a configuration, the disappearance of the IOD eastern pole in late November of year 0 enables the development of a westerly wind anomaly in the western Pacific, which also favors a positive SST anomaly in the central Pacific at the beginning of year 1 (Izumo et al. 2015). The negative T300 anomaly that appears in the eastern Pacific during the easterly wind anomaly, with signs of eastward propagation and followed by positive heat content anomalies in late winter and spring (at the beginning of year 1), is qualitatively consistent with the equatorial wave response described by Izumo et al. $(2010,2015)$.

To assess the aforementioned mechanism in the CMIP5 models, we separately consider the CMIP5 models that clearly show a delayed IOD-ENSO relationship and the models that do not, that is, the upper and lower terciles (seven models in each tercile) in terms of enhanced predictability resulting from the inclusion of DMI as a predictor of the following year's ENSO (according to Fig. 6). Figure 9 shows that the models displaying the strongest IOD influence on the following year's ENSO also display signals that are consistent with the observations in terms of upper ocean heat content (see T300 in Figs. 9a,b). By contrast, anomalies are weaker in CMIP5 models with a weak IOD influence on the following year's ENSO (Fig. 9b). The heat content in these models clearly displays a warm water buildup in the western Pacific during the IOD event, as well as a deepening of the thermocline in the central Pacific shortly after the end of the IOD-induced easterly anomalies in the central Pacific. This easterly wind anomaly in the western Pacific, however, begins much earlier in the CMIP5 model mean than in SODA: the CMIP5 multimodel mean easterly anomaly is already well developed during the buildup of the IOD event and decays at its peak, whereas the SODA easterly anomaly grows synchronously with the IOD event. These decaying easterlies during the development of the IOD event coincide with significant negative SST anomalies in the Pacific. Moreover, the western Pacific wind anomaly in DJF of year 0 and 1 also displays a different behavior in CMIP5 models and observations. The shift from easterly to westerly anomalies occurs later in the CMIP5 models (around January-February; Figs. 9a,b) than in the observations (around October-November; Fig. 9c). In summary, despite realistic relationship between the IOD and the following year's ENSO, the physical mechanism of this interaction remains elusive in the CMIP5 models, and further work (e.g., investigating the mechanisms for each CMIP model separately) will be needed to identify other processes that may affect the IOD-ENSO interactions.

To investigate asymmetries in the mechanism described in Fig. 9, we have built composites anomalies by subtracting composites of each ENSO phase (La Niña, neutral, El Niño) from composites of pIOD cooccurring with these ENSO phases (pIOD-La Niña, pIOD-neutral, and pIOD-El Niño respectively), and similarly for nIOD co-occurring with these ENSO phases. The results (not shown) corroborate the linear regression analysis above and do not suggest a strong asymmetry between pIOD- and nIOD-related mechanisms (the signatures of ENSO are only $\sim 15 \%$ stronger for the years following a pIOD than for the years following a nIOD).

\section{Discussion}

This paper brings further evidence that observed pIODs (nIODs) tend to be followed by La Niña (El Niño) events 14 months later. These delayed sequences are also present in a majority of the 21 CMIP5 models examined in this paper. Two statistical tests developed in this paper show that a physical mechanism is needed to explain the delayed pIOD-La Niña transition in the observations and in most CMIP5 models, although the ENSO effect on the synchronous IOD and tendency of La Niñas to follow El Niños clearly favors this transition. This physical mechanism, however, remains elusive in the CMIP5 models. 


\section{a. Discussion of the physical mechanism in the observations}

The 1890-2008 IOD-induced wind anomaly over the Pacific starts $3-4$ months earlier and is $2-3$ times weaker than in Izumo et al. (2010). This may be related to the use of 20CR in our analysis [instead of NCEP-2 in Izumo et al. (2010)] because we note similar differences over 1980-2008 as over 1890-2008 in Figs. 9c and 9d. The warm water buildup in SODA and the associated SST anomalies over 1890-2008 are approximately half the magnitude of those over 1980-2008 (which are similar to those found by Izumo et al. over a similar period). It is difficult to know whether this smaller amplitude over the entire period arises from possible biases in the first half of the SODA and 20CR reanalyses or from interdecadal variability in the delayed IOD-ENSO relationship [Izumo et al. (2014) have suggested that the IOD influence was weaker during the mid-twentieth century]. Nonetheless, our analysis suggests that the mechanism proposed by Izumo et al. (2010) may operate over the entire 1890-2008 period, but probably with significant interdecadal variations.

Despite some consistency with Izumo et al. (2010) mechanism, the exact timing of the development of westerly anomalies over the Pacific (Figs. 9c,d at the end of year 0) is puzzling. Indeed, the transition from easterly to westerly anomaly occurs in October-November, slightly before the end of the Indian Ocean warm anomaly. These westerly anomalies become well developed over the western Pacific approximately at the same time as Pacific positive SST anomalies around the date line (i.e., in December-January). As shown in Figs. $9 \mathrm{c}$ and $9 \mathrm{~d}$, these westerly anomalies in winter are not related to any significant SST signal in the Indian Ocean (such as the IOB). Nonetheless, it is possible that the development of westerly anomalies occurs through a physical mechanism that is more complex than previously described. Another source of uncertainty is of course the linear nature of the statistical analyses such as that of Fig. 9, which may not properly capture, for example, asymmetries between positive and negative events or thresholds in the convection response to SST anomalies.

\section{b. Discussion of the difference between observations and CMIP5}

It is important to question whether the physical mechanism operating in CMIP5 models and observations are the same. The systematic overestimation of the IOD amplitude in CMIP5 models (Fig. 2) may indeed imply an overly strong atmospheric response and therefore an overestimation of the asynchronous IOD-ENSO relationship in CMIP5. The overly strong IOD in CMIP5 might, for example, explain why a physical mechanism is needed to explain the delayed nIOD-El Niño transition in a majority of CMIP5 models but not in some observational products (section 4c). However, the absence of a significant correlation between the DMI amplitude and the 14-month lagged DMI-Niño-3.4 correlation across the CMIP5 models $(r=0.04$, not shown) suggests that this is not the case. This nonsignificant correlation could be related to the fact that the western Pacific wind sensitivity to the IOD amplitude varies across models (e.g., due to different convection schemes and SST mean states, which affect the threshold for convection). In addition, even if the wind response to the IOD amplitude were the same in every models, Bellenger et al. (2014) have shown that there is a large model dispersion in terms of Bjerknes feedback and therefore in ENSO response to wind anomalies. Similarly, the probabilities of randomly obtaining each delayed transition (Fig. 8) are not significantly rank-correlated with the DMI amplitude ( $r=0.25$ and $r=-0.05$ for pIOD-La Niña and nIOD-El Niño, respectively). This suggests that the overestimation of the IOD amplitude is not the main reason for the prevalence of a delayed IODENSO relationship in the CMIP5 models.

The second major concern about the mechanism in CMIP5 models is that there are differences in the details of the timing of IOD-induced wind anomalies compared to observations. In section 4, we have reported that the easterly wind anomaly in the western Pacific begins much earlier in the CMIP5 models than in SODA. Going back to Fig. 5, we can see that approximately half of the CMIP5 models display a moderate correlation between DMI and the previous year's Niño-3.4, which is not found in observations. As suggested in section 3, this could be partially related to ENSO events lasting too long in some models. Using a similar methodology as in Fig. 9, we removed the linear influence of the previous year's ENSO (either in $\mathrm{ND}_{y-1} \mathrm{~J}_{y 0}$ or in $\mathrm{MJJ}_{y 0}$ ). The pattern is almost unchanged compared to Fig. 9, although weakened for the top CMIP5 models (not shown). This negative SST anomaly does not appear to emerge from a previous ENSO, but peaks in June. We have found that this SST anomaly co-occurs with decreased convection and enhanced subsidence in the western-central equatorial Pacific and increased convection over the Maritime Continent (and hence an amplification of the Walker circulation considering the cold tongue bias of CMIP5 models; not shown) but its origin remains unclear and understanding its effects on the winds would require specific modeling work. Another difference between the observations and the CMIP5 models is that the shift from easterly to westerly 
wind anomaly in the western Pacific occurs later in the CMIP5 models than in the observations. This bias is possibly partly related to the IOD eastern pole SST anomaly lasting longer in CMIP5 models (until $\sim$ DecemberJanuary) than in observations (until about November).

Further analyses will be necessary to understand whether these differences lead to fundamentally distinct mechanisms. A possible strategy would be to select the CMIP5 models showing the best agreement with observations in terms of Indo-Pacific relationship and then to perform ensemble experiments from neutral, discharged, and recharged Pacific WWV with either a climatological SST, pure IOD, or pure IOB pattern specified in the Indian Ocean.

Finally, it has been shown that even though a physical mechanism is required to explain the delayed IODENSO relationship in the CMIP5 models, a part of this relationship is favored by the intrinsic properties of ENSO temporal sequences and the synchronous ENSOIOD relationship (sections $4 b, c)$. From this point of view, the overestimated occurrence of El Niño-La Niña transitions in the CMIP5 models (Fig. 4a) tends to favor the occurrence of delayed pIOD-La Niña transitions. However, the underestimated occurrence of synchronous pIOD-El Niño in the CMIP5 models (Fig. 4b) has the opposite effect on the occurrence of delayed pIOD-La Niña transitions. These different statistical properties between CMIP5 models and observations further complicate the comparison between the physical mechanism in the observations and in the CMIP5 models.

\section{c. Limitations of this study}

The present study has only considered the role of IOD on ENSO transitions. Nonetheless, we would like to point out that the present study does not rule out the influence of the IOB on the Pacific evolution. Indeed, this influence has been shown to be important for ENSO transitions (Kug and Kang 2006; Ohba and Ueda 2007, 2009a; Kug and Ham 2012; Santoso et al. 2012; Ohba and Watanabe 2012; Dayan et al. 2015). However, it is very difficult to isolate the role of ENSO from the role of IOB on the following year's ENSO using simple statistical techniques. Indeed, the covariance between synchronous NDJ Niño-3.4 and January-February TIO is $60 \%$ in the observations and $45 \%$ in the CMIP5 multimodel mean, whereas the covariance between SON DMI and the following JF TIO is only $\sim 25 \%$ in both the observations and the CMIP5 multimodel mean (not shown), and the covariance between SON DMI and Niño-3.4 of the same year is also $\sim 25 \%$. This supports the idea that the IOB can to a large extent be considered as an intrinsic part of ENSO while the IOD is more independent from both ENSO and the IOB. This is the assumption that has been made along the previous subsections. In other words, what we have previously called "intrinsic properties of ENSO temporal sequence" (in particular in the two statistical approaches used in section 4) is not purely intrinsic (in the sense of its usual description limited to the Pacific) but may partly result from interactions with the IOB.

Because of the high covariance of synchronous Niño3.4 and TIO, it is very difficult to distinguish the roles of ENSO and the IOB in our methodologies. We have attempted to remove the influence of the IOB in the composites of Fig. 9 (i.e., calculating the multilinear regression $Y=a \overline{\mathrm{DMI}}+b \overline{\mathrm{NINO} 34}+c \overline{\mathrm{TIO}}$, then plotting $a$ ). However, the multilinear regression appears to be very similar to the one plotted in Fig. 9 (not shown). Again, we do not claim that the IOB has no influence on the following year's ENSO, but as Niño-3.4 and TIO are highly correlated, removing the Niño-3.4 signal already removes a large part of the TIO signal. To properly compare the roles of the IOD and IOB on the following year's ENSO, a sensible method would probably be to run partially coupled experiments that are specifically designed to answer this question. Such dedicated coupled experiments, using the CMIP models that reproduce the ENSO-IOD relations well, would also probably allow us to investigate the mechanisms of the Indian Ocean influence of ENSO beyond what could be achieved through the linear statistical analyses of the present paper. However, this is beyond the scope of this paper.

Beyond the role of the IOB, a further limitation of our study is that we have only analyzed the physical mechanisms in terms of an "atmospheric bridge" as in Izumo et al. (2010). Some authors have suggested that a mechanism through the Indonesian Throughflow (oceanic bridge) could better explain the delayed IOD-ENSO relationship than the atmospheric bridge (Yuan et al. 2011, 2013), while other studies suggest that this oceanic bridge has only a marginal influence (e.g., Clarke 1991; Schwarzkopf and Böning 2011; Izumo et al. 2015; Kajtar et al. 2015). While we have not attempted to examine this oceanic mechanism, we have shown that the atmospheric bridge is effective and statistically robust in the CMIP5 models and, to a less robust extent, in the observations.

\section{d. Implications for ENSO predictions}

Most studies dedicated to dynamical ENSO forecasts based on ocean-atmosphere models have, so far, not attempted to extend their forecasts beyond the spring barrier (i.e., 9 months ahead of ENSO peak; e.g., Barnston and Tippett 2013; Ham et al. 2014), with a few exceptions (e.g., Luo et al. 2008). Our study, however, suggests that most CMIP5 models do reproduce a contribution of Indian Ocean variability to ENSO 
predictability at leads of up to $\sim 14$ months prior to the ENSO peak. We have shown that this additional predictability is not purely a statistical artifact arising from, for example, the tendency of El Niños to induce a synchronous pIOD in the Indian Ocean and to be followed by a La Niña. Even if the physical mechanism that explains this increased ENSO predictability requires further scrutiny, this ability of many CMIP5 models to reproduce the 14-month lead influence of the IOD on the Pacific Ocean is a strong incentive to explore extendedrange dynamical forecasts of ENSO.

Finally, we would like to emphasize that the IOD has more potential than the IOB in terms of ENSO forecast. An ENSO prediction based on TIO (the IOB index; see section 2) can only be issued in January-February because TIO is less robust before that season. Hence this would be a prediction $\sim 11$ months ahead, while the DMI allows predictions $\sim 14$ months ahead. Notwithstanding this 3-month forecast delay, we have calculated the increase of ENSO explained variance when including January-February (JF) TIO as a predictor of ENSO in addition to the JF warm water volume (WWV). The predictability of ENSO from WWV is much higher for WWV in JF than for WWV in SON (not shown). As a result, including JF TIO as a second predictor does not enhance the predictability of ENSO as much as SON DMI. Indeed, Including JF TIO as a predictor increases the explained Niño-3.4 variance in SODA by less than $9 \%$ while including SON DMI increases that variance by $20 \%$ (Fig. 6). The explained Niño-3.4 variance in the CMIP5 multimodel mean is also much weaker for JF TIO as a predictor than for SON DMI (5\% vs $12 \%$ in Fig. 6), and the increased explained Niño-3.4 variance is only significant at the $90 \%$ level in five models for JF TIO versus 16 models for SON DMI (see legend of Fig. 6). Thus it appears that the SON IOD has more potential than the JF IOB in terms of ENSO forecasts (given that $\mathrm{WWV}$ is also used as a predictor).

\section{Conclusions}

In this paper, we have first used extended observational time series and output from 21 CMIP5 historical model simulations to describe the properties of ENSO sequences and the co-occurrence between synchronous IOD and ENSO events. In the observations as in the CMIP5 models, $\sim 40 \%$ of El Niño events are followed by La Niña, a significantly larger proportion than that expected from a random sequence $(25 \%)$, while the proportion of La Niña events followed by El Niño ( 25\%) is not distinguishable from a random distribution at the $90 \%$ significance level. Most models reproduce the observed tendency of IOD events to co-occur with synchronous ENSO events. There is also a clear transition asymmetry in this synchronous relationship, whereby the proportion of pIODs co-occurring with an El Niño $(\sim 50 \%-60 \%)$ is significantly higher than the proportion of nIODs co-occurring with a La Niña $(\sim 40 \%)$ in both the observations and CMIP5 models.

This paper has further addressed the possible influence of IODs on the following year's ENSO. Nearly all CMIP5 models produce a robust relationship between IOD and the following year's (i.e., 14 months later) ENSO, with a multimodel mean lag correlation of -0.40 as in the observations. Consequently, the predictability of ENSO from a linear combination of DMI and the Pacific warm water volume in the previous year is enhanced compared to the predictability of ENSO from the Pacific warm water volume only. The enhanced predictability corresponds to $13 \%$ in explained ENSO variance for the CMIP5 multimodel mean and to $22 \%$ for the 120-yr SODA ocean reanalysis. We have also found that the proportion of pIODs followed by a La Niña 14 months later $(\sim 45 \%)$ is greater than the proportion of nIODs followed by an El Niño 14 months later $(\sim 30 \%-40 \%)$ both in the CMIP5 models and in the observations, but the consequences of this asymmetry in terms of operational forecasts are very limited.

Two statistical tests were developed to examine if the delayed IOD-ENSO relationship can arise solely from intrinsic properties of the ENSO temporal sequences (i.e., the tendency of El Niños to be followed by La Niñas) and the synchronous IOD-ENSO relationship (i.e., without the need to invoke a physical mechanism whereby an IOD event causes a response in the equatorial Pacific that interferes with the ENSO dynamics). The probability of pIODs leading La Niña events by 14 months is significantly larger than what would be expected from ENSO sequences and synchronous IOD-ENSO relationship in all the observational products and in 15 out of 21 CMIP5 models. The probability of nIOD events leading El Niños by 14 months is also larger than that derived from the properties of ENSO temporal sequences and of synchronous IOD-ENSO transitions in 12 out of 21 CMIP5 models and in one observational product.

The main conclusion of this paper is therefore that a physical mechanism is needed to explain the delayed pIOD-La Niña transition in the observations and in most CMIP5 models, even though the tendency of El Niños to induce synchronous pIODs and to be followed by La Niñas clearly favors this transition. A mechanism is also needed to explain the delayed nIOD-El Niño relationship in 12 out of 21 CMIP5 models. But no such mechanism is needed to explain the delayed nIOD-El Niño relationship in the nine other models, and there is no consensus for this transition in the observations. The 
analyses in this paper are broadly consistent with Izumo et al.'s (2010, 2015) mechanisms, although several inconsistencies do not really allow us to draw unambiguous conclusions about a common mechanism across observational datasets and CMIP models.

Acknowledgments. This study was conducted in the context of the ARC project DP110100601 and the Agence Nationale de la Recherche (ANR) project METRO (2010-BLAN-616-01). This work was supported by the NCI National Facility at the ANU via the provision of computing resources to the ARC Centre of Excellence for Climate System Science. We acknowledge the World Climate Research Program's Working Group on Coupled Modelling, which is responsible for CMIP, and we thank the climate modeling groups (Table 1) for producing and making their model output available. Support for the Twentieth Century Reanalysis project dataset is provided by the U.S. Department of Energy, Office of Science Innovative and Novel Computational Impact on Theory and Experiment (DOE INCITE) program, and the Office of Biological and Environmental Research (BER), and by the National Oceanic and Atmospheric Administration Climate Program Office. We also acknowledge the following centers for making their data available: the TAO Project Office, NOAA/PMEL for their WWV estimates, the University of Maryland for SODA, the Met Office for HadSST2 and HadISST, NOAA for ERSST, and the Japan Meteorological Agency for COBE SST.

\section{REFERENCES}

An, S.-I., and B. Wang, 2000: Interdecadal change of the structure of the ENSO mode and its impact on the ENSO frequency. J. Climate, 13, 2044-2055, doi:10.1175/1520-0442(2000)013<2044: ICOTSO $>2.0 . \mathrm{CO} ; 2$.

Annamalai, H., R. Murtugudde, J. Potemra, S. P. Xie, P. Liu, and B. Wang, 2003: Coupled dynamics over the Indian Ocean: Spring initiation of the zonal mode. Deep-Sea Res. II, 50, 23052330, doi:10.1016/S0967-0645(03)00058-4.

- S. P. Xie, J. P. McCreary, and R. Murtugudde, 2005: Impact of Indian Ocean sea surface temperature on developing El Niño. J. Climate, 18, 302-319, doi:10.1175/JCLI-3268.1.

Ashok, K., Z. Guan, and T. Yamagata, 2003: A look at the relationship between the ENSO and the Indian Ocean dipole. J. Meteor. Soc. Japan, 81, 41-56, doi:10.2151/jmsj.81.41.

Barnston, A. G., and M. K. Tippett, 2013: Predictions of Niño3.4 SST in CFSv1 and CFSv2: A diagnostic comparison. Climate Dyn., 41, 1615-1633, doi:10.1007/s00382-013-1845-2.

Behera, S. K., J. J. Luo, S. Masson, S. A. Rao, H. Sakuma, and T. Yamagata, 2006: A CGCM study on the interaction between IOD and ENSO. J. Climate, 19, 1688-1705, doi:10.1175/ JCLI3797.1.

Bellenger, H., E. Guilyardi, J. Leloup, M. Lengaigne, and J. Vialard, 2014: ENSO representation in climate models: From CMIP3 to CMIP5. Climate Dyn., 42, 1999-2018, doi:10.1007/s00382-013-1783-z.
Bentsen, M., and Coauthors, 2012: The Norwegian Earth System Model, NorESM1-M-Part 1: Description and basic evaluation. Geosci. Model Dev. Discuss., 5, 2843-2931, doi:10.5194/ gmdd-5-2843-2012.

Bjerknes, J., 1969: Atmospheric teleconnections from the equatorial Pacific. Mon. Wea. Rev., 97, 163-172, doi:10.1175/ 1520-0493(1969)097<0163:ATFTEP > 2.3.CO;2.

BOM, 2010: Operational implementation of the ACCESS numerical weather prediction system. NMOC Operations Bull. 83, 34 pp. [Available online at http://www.bom.gov.au/ australia/charts/bulletins/apob83.pdf.]

Bracco, A., F. Kucharski, F. Molteni, W. Hazeleger, and C. Severijns, 2005: Internal and forced modes of variability in the Indian Ocean. Geophys. Res. Lett., 32, L12707, doi:10.1029/2005GL023154.

Burgers, G., 1999: The El Niño stochastic oscillator. Climate Dyn., 15, 521-531, doi:10.1007/s003820050297.

, and D. B. Stephenson, 1999: The "normality" of El Niño. Geophys. Res. Lett., 26, 1027-1030, doi:10.1029/1999GL900161.

Cai, W., and T. Cowan, 2013: Why is the amplitude of the Indian Ocean dipole overly large in CMIP3 and CMIP5 climate models? Geophys. Res. Lett., 40, 1200-1205, doi:10.1002/grl.50208.

—, P. van Rensch, T. Cowan, and H. H. Hendon, 2012: An asymmetry in the IOD and ENSO teleconnection pathway and its impact on Australian climate. J. Climate, 25, 63186329, doi:10.1175/JCLI-D-11-00501.1.

Carton, J. A., and B. S. Giese, 2008: A reanalysis of ocean climate using Simple Ocean Data Assimilation (SODA). Mon. Wea Rev., 136, 2999-3017, doi:10.1175/2007MWR1978.1.

Choi, K.-Y., G. A. Vecchi, and A. T. Wittenberg, 2013: ENSO transition, duration, and amplitude asymmetries: Role of the nonlinear wind stress coupling in a conceptual model. J. Climate, 26, 9462-9476, doi:10.1175/JCLI-D-13-00045.1.

Chylek, P., J. Li, M. K. Dubey, M. Wang, and G. Lesins, 2011: Observed and model simulated 20th century Arctic temperature variability: Canadian Earth System Model CanESM2. Atmos. Chem. Phys. Discuss., 11, 22 893-22 907, doi:10.5194/ acpd-11-22893-2011.

Clarke, A. J., 1991: On the reflection and transmission of lowfrequency energy at the irregular western Pacific Ocean boundary. J. Geophys. Res., 96, 3289-3305, doi:10.1029/90JC00985.

__ 2014: El Niño physics and El Niño predictability. Annu. Rev. Mar. Sci., 6, 79-99, doi:10.1146/annurev-marine-010213-135026.

_ using a space-time integration of Indo-Pacific winds and equatorial Pacific upper ocean heat content. Geophys. Res. Lett., 30, 1399, doi:10.1029/2002GL016673.

Collins, M., S. Tett, and C. Cooper, 2001: The internal climate variability of HadCM3, a version of the Hadley Centre coupled model without flux adjustments. Climate Dyn., 17, 61-81, doi:10.1007/s003820000094.

_ - and Coauthors, 2010: The impact of global warming on the tropical Pacific Ocean and El Niño. Nat. Geosci., 3, 391-397, doi:10.1038/ngeo868.

Collins, W., and Coauthors, 2011: Development and evaluation of an Earth-system model-HadGEM2. Geosci. Model Dev. Discuss, 4, 997-1062, doi:10.5194/gmdd-4-997-2011.

Compo, G. P., and Coauthors, 2011: The Twentieth Century Reanalysis Project. Quart. J. Roy. Meteor. Soc., 137, 1-28, doi:10.1002/qj.776.

Dayan, H., T. Izumo, J. Vialard, and M. Lengaigne, 2014: Does sea surface temperature outside the tropical Pacific contribute to enhanced ENSO predictability? Climate Dyn., 43, 1311-1325, doi:10.1007/s00382-013-1946-y. 
,,,---- , and S. Masson, 2015: Do regions outside the tropical Pacific influence ENSO through atmospheric teleconnections? Climate Dyn., 45, 583-601, doi:10.1007/ s00382-014-2254-x.

Donner, L. J., and Coauthors, 2011: The dynamical core, physical parameterizations, and basic simulation characteristics of the atmospheric component AM3 of the GFDL global coupled model CM3. J. Climate, 24, 3484-3519, doi:10.1175/2011JCLI3955.1.

Dufresne, J.-L., and Coauthors, 2013: Climate change projections using the IPSL-CM5 Earth System Model: From CMIP3 to CMIP5. Climate Dyn., 40, 2123-2165, doi:10.1007/ s00382-012-1636-1.

Fischer, A. S., P. Terray, E. Guilyardi, S. Gualdi, and P. Delecluse, 2005: Two independent triggers for the Indian Ocean dipole/ zonal mode in a coupled GCM. J. Climate, 18, 3428-3449, doi:10.1175/JCLI3478.1.

Gent, P. R., and Coauthors, 2011: The Community Climate System Model version 4. J. Climate, 24, 4973-4991, doi:10.1175/ 2011JCLI4083.1.

Ham, Y.-G., S. Schubert, Y. Vikhliaev, and M. J. Suarez, 2014: An assessment of the ENSO forecast skill of GEOS-5 system. Climate Dyn., 43, 2415-2430, doi:10.1007/s00382-014-2063-2.

Ishii, M., A. Shouji, S. Sugimoto, and T. Matsumoto, 2005: Objective analyses of sea-surface temperature and marine meteorological variables for the 20th century using ICOADS and the Kobe Collection. Int. J. Climatol., 25, 865-879, doi:10.1002/ joc.1169.

Izumo, T., and Coauthors, 2010: Influence of the state of the Indian Ocean dipole on the following year's El Niño. Nat. Geosci., 3, 168-172, doi:10.1038/ngeo760.

_- M. Lengaigne, J. Vialard, J.-J. Luo, T. Yamagata, and G. Madec, 2014: Influence of Indian Ocean dipole and Pacific recharge on following year's El Niño: Interdecadal robustness. Climate Dyn., 42, 291-310, doi:10.1007/s00382-012-1628-1.

_, J. Vialard, H. Dayan, M. Lengaigne, and I. Suresh, 2015: A simple estimation of equatorial Pacific response from windstress to untangle Indian Ocean dipole and basin influences on El Niño. Climate Dyn., doi:10.1007/s00382-015-2700-4, in press.

Jin, F.-F., 1997: An equatorial ocean recharge paradigm for ENSO. Part I: Conceptual model. J. Atmos. Sci., 54, 811-829, doi:10.1175/1520-0469(1997)054<0811:AEORPF>2.0.CO;2.

_- S.-I. An, A. Timmermann, and J. Zhao, 2003: Strong El Niño events and nonlinear dynamical heating. Geophys. Res. Lett., 30, 1120, doi:10.1029/2002GL016356.

Jourdain, N. C., A. Sen Gupta, A. S. Taschetto, C. C. Ummenhofer, A. F. Moise, and K. Ashok, 2013: The Indo-Australian monsoon and its relationship to ENSO and IOD in reanalysis data and the CMIP3/CMIP5 simulations. Climate Dyn., 41, 30733102, doi:10.1007/s00382-013-1676-1.

Kajtar, J. B., A. Santoso, M. H. England, and W. Cai, 2015: Indo-Pacific climate interactions in the absence of an Indonesian Throughflow. J. Climate, 28, 5017-5029, doi:10.1175/ JCLI-D-14-00114.1.

Kim, S. T., and J.-Y. Yu, 2012: The two types of ENSO in CMIP5 models. Geophys. Res. Lett., 39, L11704, doi:10.1029/ 2012 GL052006.

Klein, S. A., B. J. Soden, and N.-C. Lau, 1999: Remote sea surface temperature variations during ENSO: Evidence for a tropical atmospheric bridge. J. Climate, 12, 917-932, doi:10.1175/ 1520-0442(1999)012<0917:RSSTVD>2.0.CO;2.

Kug, J.-S., and I.-S. Kang, 2006: Interactive feedback between ENSO and the Indian Ocean. J. Climate, 19, 1784-1801, doi:10.1175/JCLI3660.1.
— , and Y.-G. Ham, 2012: Indian Ocean feedback to the ENSO transition in a multimodel ensemble. J. Climate, 25, 69426957, doi:10.1175/JCLI-D-12-00078.1.

Lee, T., and M. J. McPhaden, 2010: Increasing intensity of El Niño in the central-equatorial Pacific. Geophys. Res. Lett., 37, L14603, doi:10.1029/2010GL044007.

Leloup, J. A., M. Lengaigne, and J.-P. Boulanger, 2008: Twentieth century ENSO characteristics in the IPCC database. Climate Dyn., 30, 277-291, doi:10.1007/s00382-007-0284-3.

Li, T., B. Wang, C. P. Chang, and Y. Zhang, 2003: A theory for the Indian Ocean dipole-zonal mode. J. Atmos. Sci., 60, 2119-2135, doi:10.1175/1520-0469(2003)060<2119:ATFTIO>2.0.CO;2.

Liu, L., S.-P. Xie, X.-T. Zheng, T. Li, Y. Du, G. Huang, and W.-D. Yu, 2014: Indian Ocean variability in the CMIP5 multi-model ensemble: The zonal dipole mode. Climate Dyn., 43, 17151730, doi:10.1007/s00382-013-2000-9.

Luo, J.-J., S. Masson, S. K. Behera, and T. Yamagata, 2008: Extended ENSO predictions using a fully coupled oceanatmosphere model. J. Climate, 21, 84-93, doi:10.1175/ 2007JCLI1412.1.

_- R. Zhang, S. K. Behera, Y. Masumoto, F.-F. Jin, R. Lukas, and T. Yamagata, 2010: Interaction between El Niño and extreme Indian ocean dipole. J. Climate, 23, 726-742, doi:10.1175/2009JCLI3104.1.

Martin, G. M., and Coauthors, 2011: The HadGEM2 family of Met Office Unified Model Climate configurations. Geosci. Model Dev. Discuss., 4, 765-841, doi:10.5194/gmdd-4-765-2011.

McPhaden, M. J., 2012: A 21st century shift in the relationship between ENSO SST and warm water volume anomalies. Geophys. Res. Lett., 39, L09706, doi:10.1029/2012GL051826.

_ , and M. Nagura, 2014: Indian Ocean dipole interpreted in terms of recharge oscillator theory. Climate Dyn., 42, 15691586, doi:10.1007/s00382-013-1765-1.

_ S. E. Zebiak, and M. H. Glantz, 2006: ENSO as an integrating concept in Earth science. Science, 314, 1740-1745, doi:10.1126/ science. 1132588 .

Meehl, G. A., 1987: The annual cycle and interannual variability in the tropical Pacific and Indian Ocean regions. Mon. Wea. Rev., 115, 2750, doi:10.1175/1520-0493(1987)115<0027:TACAIV>2.0.CO;2.

Meinen, C. S., and M. J. McPhaden, 2000: Observations of warm water volume changes in the equatorial Pacific and their relationship to El Niño and La Niña. J. Climate, 13, 3551-3559, doi:10.1175/1520-0442(2000)013<3551:OOWWVC $>2.0 . C O ; 2$.

Murtugudde, R., J. P. McCreary, and A. J. Busalacchi, 2000: Oceanic processes associated with anomalous events in the Indian Ocean with relevance to 1997-1998. J. Geophys. Res., 105 (C2), 3295-3306, doi:10.1029/1999JC900294.

Ohba, M., and H. Ueda, 2005: Basin-wide warming in the equatorial Indian Ocean associated with El Niño. SOLA, 1, 89-92, doi:10.2151/sola.2005-024.

_, and - 2007: An impact of SST anomalies in the Indian Ocean in acceleration of the El Niño to La Niña transition. J. Meteor. Soc. Japan, 85, 335-348, doi:10.2151/jmsj.85.335.

$\longrightarrow$, and — 2009a: Role of nonlinear atmospheric response to SST on the asymmetric transition process of ENSO.J. Climate, 22, 177-192, doi:10.1175/2008JCLI2334.1.

$\longrightarrow$, and $-2009 \mathrm{~b}$ : Seasonally different response of the Indian Ocean to the remote forcing of El Niño: Linking the dynamics and thermodynamics. SOLA, 5, 176-179, doi:10.2151/ sola.2009-045.

, and M. Watanabe, 2012: Role of the Indo-Pacific interbasin coupling in predicting asymmetric ENSO transition and duration. J. Climate, 25, 3321-3335, doi:10.1175/JCLI-D-11-00409.1. 
D. Nohara, and H. Ueda, 2010: Simulation of asymmetric ENSO transition in WCRP CMIP3 multimodel experiments. J. Climate, 23, 6051-6067, doi:10.1175/2010JCLI3608.1.

Okumura, Y. M., M. Ohba, C. Deser, and H. Ueda, 2011: A proposed mechanism for the asymmetric duration of El Niño and La Niña. J. Climate, 24, 3822-3829, doi:10.1175/2011JCLI3999.1.

Picaut, J., F. Masia, and Y. Du Penhoat, 1997: An advectivereflective conceptual model for the oscillatory nature of the ENSO. Science, 277, 663-666, doi:10.1126/science.277.5326.663.

Raddatz, T., and Coauthors, 2007: Will the tropical land biosphere dominate the climate-carbon cycle feedback during the twenty-first century? Climate Dyn., 29, 565-574, doi:10.1007/ s00382-007-0247-8.

Rayner, N. A., D. E. Parker, E. B. Horton, C. K. Folland, L. V. Alexander, D. P. Rowell, E. C. Kent, and A. Kaplan, 2003: Global analyses of sea surface temperature, sea ice, and night marine air temperature since the late nineteenth century. J. Geophys. Res., 108 (D14), 4407, doi:10.1029/2002JD002670. , P. Brohan, D. E. Parker, C. K. Folland, J. J. Kennedy, M. Vanicek, T. J. Ansell, and S. F. B. Tett, 2006: Improved analyses of changes and uncertainties in sea surface temperature measured in situ since the mid-nineteenth century: The HadSST2 dataset. J. Climate, 19, 446-469, doi:10.1175/JCLI3637.1.

Reverdin, G., D. L. Cadet, and D. Gutzler, 1986: Interannual displacements of convection and surface circulation over the equatorial Indian Ocean. Quart. J. Roy. Meteor. Soc., 112, 43 67, doi:10.1002/qj.49711247104.

Saji, N. H., B. N. Goswami, P. N. Vinayachandran, and T. Yamagata, 1999: A dipole mode in the tropical Indian Ocean. Nature, 401, 360-363.

Santoso, A., M. H. England, and W. Cai, 2012: Impact of IndoPacific feedback interactions on ENSO dynamics diagnosed using ensemble climate simulations. J. Climate, 25, 7743-7763, doi:10.1175/JCLI-D-11-00287.1.

Schmidt, G. A., and Coauthors, 2006: Present-day atmospheric simulations using GISS ModelE: Comparison to in situ, satellite, and reanalysis data. J. Climate, 19, 153-192, doi:10.1175/ JCLI3612.1.

Schwarzkopf, F. U., and C. W. Böning, 2011: Contribution of Pacific wind stress to multi-decadal variations in upper-ocean heat content and sea level in the tropical south Indian Ocean. Geophys. Res. Lett., 38, L12602, doi:10.1029/2011GL047651.

Smith, T. M., R. W. Reynolds, T. C. Peterson, and J. Lawrimore, 2008: Improvements to NOAA's historical merged landocean surface temperature analysis (1880-2006). J. Climate, 21, 2283-2296, doi:10.1175/2007JCLI2100.1.

Tang, Y., and Z. Deng, 2010: Tropical Pacific upper ocean heat content variations and ENSO predictability during the period from 1881-2000. Ocean Science, Advances in Geosciences Series, Vol. 18, World Scientific, 87-108.

Taschetto, A. S., A. Sen Gupta, N. C. Jourdain, A. Santoso, C. C. Ummenhofer, and M. H. England, 2014: Cold tongue and warm pool ENSO events in CMIP5: Mean state and future projections. J. Climate, 27, 2861-2885, doi:10.1175/JCLI-D-13-00437.1.

Taylor, K. E., R. J. Stouffer, and G. A. Meehl, 2011: An overview of CMIP5 and the experiment design. Bull. Amer. Meteor. Soc., 93, 485-498, doi:10.1175/BAMS-D-11-00094.1.

Tozuka, T., J.-J. Luo, S. Masson, and T. Yamagata, 2007: Decadal modulations of the Indian Ocean dipole in the SINTEX-F1 coupled GCM. J. Climate, 20, 2881-2894, doi:10.1175/JCLI4168.1.

Trenberth, K. E., G. W. Branstator, D. Karoly, A. Kumar, N.-C. Lau, and C. Ropelewski, 1998: Progress during TOGA in understanding and modeling global teleconnections associated with tropical sea surface temperatures. J. Geophys. Res., 103 (C7), 14 291-14324, doi:10.1029/97JC01444.

Ummenhofer, C. C., M. H. England, P. C. McIntosh, G. A. Meyers, M. J. Pook, J. S. Risbey, A. Sen Gupta, and A. S. Taschetto, 2009: What causes southeast Australia's worst droughts? Geophys. Res. Lett., 36, L04706, doi:10.1029/2008GL036801.

Voldoire, A., and Coauthors, 2013: The CNRM-CM5. 1 global climate model: Description and basic evaluation. Climate Dyn., 40, 2091-2121, doi:10.1007/s00382-011-1259-y.

Volodin, E. M., N. A. Dianskii, and A. V. Gusev, 2010: Simulating present-day climate with the INMCM4. 0 coupled model of the atmospheric and oceanic general circulations. Izv. Atmos Ocean. Phys., 46, 414-431, doi:10.1134/S000143381004002X.

Wang, C., and J. Picaut, 2004: Understanding ENSO physics: A review. Earth's Climate, Geophys. Monogr., Vol. 147, Amer. Geophys. Union, 21-48, doi:10.1029/147GM02.

Watanabe, M., and Coauthors, 2010: Improved climate simulation by MIROC5: Mean states, variability, and climate sensitivity. J. Climate, 23, 6312-6335, doi:10.1175/2010JCLI3679.1.

Watanabe, S., and Coauthors, 2011: MIROC-ESM: Model description and basic results of CMIP5-20c3m experiments. Geosci. Model Dev. Discuss., 4, 1063-1128, doi:10.5194/ gmdd-4-1063-2011.

Webster, P. J., A. M. Moore, J. P. Loschnigg, and R. R. Leben, 1999: Coupled ocean-atmosphere dynamics in the Indian Ocean during 1997-98. Nature, 401, 356-360, doi:10.1038/43848.

Wittenberg, A. T., 2009: Are historical records sufficient to constrain ENSO simulations? Geophys. Res. Lett, 36, L12702, doi:10.1029/2009GL038710.

Wu, B., T. Li, and T. Zhou, 2010: Asymmetry of atmospheric circulation anomalies over the western North Pacific between El Niño and La Niña. J. Climate, 23, 4807-4822, doi:10.1175/ 2010JCLI3222.1.

Wyrtki, K., 1985: Water displacements in the Pacific and the genesis of El Niño cycles. J. Geophys. Res., 90 (C4), 7129-7132, doi:10.1029/JC090iC04p07129.

Xie, S.-P., K. Hu, J. Hafner, H. Tokinaga, Y. Du, G. Huang, and T. Sampe, 2009: Indian Ocean capacitor effect on Indowestern Pacific climate during the summer following El Niño. J. Climate, 22, 730-747, doi:10.1175/2008JCLI2544.1.

Yasunaka, S., and K. Hanawa, 2011: Intercomparison of historical sea surface temperature datasets. Int. J. Climatol., 31, 10561073, doi:10.1002/joc.2104.

Yongqiang, Y., Z. Xuehong, and G. Yufu, 2004: Global coupled ocean-atmosphere general circulation models in LASG/IAP Adv. Atmos. Sci., 21, 444-455, doi:10.1007/BF02915571.

Yuan, D., and Coauthors, 2011: Forcing of the Indian Ocean dipole on the interannual variations of the tropical Pacific Ocean Roles of the Indonesian Throughflow. J. Climate, 24, 35933608, doi:10.1175/2011JCLI3649.1.

- H. Zhou, and X. Zhao, 2013: Interannual climate variability over the tropical Pacific Ocean induced by the Indian Ocean dipole through the Indonesian Throughflow. J. Climate, 26, 2845-2861, doi:10.1175/JCLI-D-12-00117.1.

Yuan, Y., and C. Li, 2008: Decadal variability of the IOD-ENSO relationship. Chin. Sci. Bull., 53, 1745-1752, doi:10.1007/ s11434-008-0196-6.

Yukimoto, S., and Coauthors, 2001: The new Meteorological Research Institute coupled GCM (MRI-CGCM 2)-Model climate and variability. Pap. Meteor. Geophys., 51, 47-88, doi:10.2467/ mripapers.51.47. 